\section{CONSTRUCCIÓN SOCIAL DE ESPACIO PÚBLICO EN BARRIOS POPULARES DE BOGOTÁ 1}

Jaime Hernández García

\section{Resumen}

El espacio público en los barrios populares, al igual que la vivienda, es en gran medida producido y transformado por los mismos habitantes. De la misma forma, estos espacios son principalmente usados por la gente que vive alrededor, con pocos 'forasteros' o visitantes haciendo uso de ellos. La materialidad observada entonces, puede decirse que corresponde largamente a las necesidades, expectativas, posibilidades y construcciones simbólicas de los habitantes de los barrios. Las prácticas sociales se transforman para acomodarse a las interacciones con el espacio público, mientras que el espacio cambia para acomodarse a esas nuevas y cambiantes interacciones sociales. Este

\section{SOCIAL CONSTRUCTION OF PUBLIC SPACE IN POPULAR NEIGHBORHOODS OF BOGOTÁ'}

Jaime Hernández García²

\begin{abstract}
As with housing, the public space of popular neighborhoods is produced and transformed by the inhabitants themselves. In the same way, a few number of "foreigners" visit these spaces, which are mainly used by local neighbors. The physical nature of these places may then be a response to the needs, expectations, possibilities and symbolic constructions of the dwellers of these areas. In this sense, social practices are transformed to adapt to the interactions with public space, while the latter, in turn, is modified to adapt to these new and changing social interactions. This paper explores the social construction of public space in popular
\end{abstract}


artículo explora la construcción social del espacio público en barrios populares de Bogotá, argumentando que existe una estrecha relación entre la gente y el espacio urbano, y que esta relación contribuye a la transformación espacial, y a la construcción de identidad individual y colectiva de los habitantes. El artículo se basa en una investigación que recoge datos de barrios populares de Bogotá, que, con un enfoque cualitativo y usando una variedad de métodos, identifica, analiza y discute las manifestaciones cotidianas, funcionales y simbólicas en los espacios públicos de los barrios populares.

\section{PALABRAS CLAVE: ASENTAMIENTOS POPULARES ESPACIO PÚBLICO Y CONSTRUCCIÓN SOCIAL DE ESPACIO.}

Fecha de recepción: 09-03-2012

Fecha de aceptación: 13-06-2013

1 Este trabajo fue desarrollado a partir de la tesis doctoral de autor: "El Parque de mi Barrio: Production and Consumption of Open Spaces in Popular Settlements in Bogotá". Investigación realizada gracias al programa de becas de alto nivel para América Latina de la Unión Europea, ALBAN, código E07D400261C0; al apoyo de la Pontificia Universidad Javeriana de Bogotá bajo el programa de Formación del Profesor Javeriano.

2 Colombia. Doctor en Arquitectura, Urbanismo y Paisajismo de la Universidad de Newcastle, Inglaterra. Profesor Asociado del Departamento de Estética de la Facultad de Arquitectura y Diseño, Pontificia Universidad Javeriana. Correo electrónico: hernandez.j@javeriana.edu.co. neighborhoods of Bogotá by arguing that there is a close relationship between people and urban space, being this linkage a contribution to both the spatial transformation and the construction of the individual and collective identity of inhabitants. This paper is based on a study that collects data on popular neighborhoods of Bogotá, using a qualitative approach to identify, analyze and discuss the different daily, functional and symbolic expressions of popular neighborhoods in public spaces.

KEYWORDS: POPULAR SETTLEMENTS, PUBLIC SPACE, SOCIAL CONSTRUCTION OF SPACE.

Received: 09-03-2012

Accepted: 13-06-2013

1 This paper is part of the doctoral thesis El Parque de mi Barrio: Production and Consumption of Open Spaces in Popular Settlements in Bogotá. This research was carried out thanks to the European Union Program of High Level Scholarship for Latin America (ALBAN) E07D400261C0 and the Pontifical Xaverian University, Bogotá, under the Xaverian Professor Training Program.

2 Colombia. PhD in Architecture, Urban Planning and Landscape, Newcastle University, England. Associate Professor, Department of Aesthetic, Faculty of Architecture and Design, Pontifical Xaverian University. Email: hernandez.j@javeriana.edu.co 


\section{Introducción}

El espacio público de los barrios populares puede verse en términos de producción y construcción social del espacio. Al igual que la vivienda, el espacio urbano en los asentamientos populares es en gran medida auto-desarrollado y muchas veces también auto-construido por los mismos habitantes. Los habitantes de los asentamientos populares, actuando individualmente o a través de grupos organizados, son los agentes principales en la producción de espacio público en los barrios. Este artículo se concentrará en la construcción social espacio urbano, que al igual que su producción, es ejercida por los mismos pobladores. Aunque son públicos en términos de acceso y propiedad, estos espacios le 'pertenecen' a la gente. La construcción social del espacio tiene que ver con la interacción de los individuos con un espacio, o como Low $^{3}$ lo expresa, con una cultura de espacialización: "El término espacialización significa ubicar —física, histórica y conceptualmente - las relaciones sociales y las prácticas sociales en un espacio". Para Rel$\mathrm{ph}^{4}$ tiene que ver con la construcción de lugar, una condición de la existencia humana: "Ser humano es tener un lugar propio". Elaborando un poco más la idea de lugar como construcción socio-espacial,

3 Low, 2000, p. 127

4 Relph, 1976, p. 1.
Holloway y Hubbard5 sostienen que "mientras la gente construye lugares, los lugares construyen a la gente" (de donde se infiere una reciprocidad entre gente y lugar). Esto se puede ver también como construcción de espacio desde la vida cotidiana: "Un espacio es sinónimo de lo que en él se vive, en el sentido de que las prácticas de la vida diaria están inmersas en lugares particulares. La práctica social está determinada por el espacio [...] La vida depende del espacio"6. A este respecto, la idea de construcción social del espacio puede ayudarnos a comprender y analizar la producción y el consumo del espacio urbano en los barrios populares, superando las visiones sobre marginalidad y pobreza a partir de las cuales se aborda generalmente. Como lo afirma Lombard ${ }^{7}$, la construcción social del espacio se puede entender como la experiencia vivida por los usuarios y productores de un lugar; como el sitio donde ocurren complejas relaciones y conflictos humanos; y como un proceso continuo que nunca termina.

Miles $^{8}$ sostiene que las acciones y los usos que se dan al espacio urbano, se convierten en 'declaraciones de identidad'. En este articulo se discute la construcción social del espacio público en los barrios populares en términos de cómo los individuos interactúan con él. En este sentido,

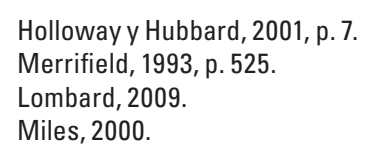


el consumo del espacio público se puede ver a través de las actividades de los habitantes que lo transforman para satisfacer sus propias necesidades. En los asentamientos populares, estas actividades están dadas en primera instancia por las prácticas sociales y culturales que se llevan a cabo en los espacios públicos. Abarcan principalmente la socialización, los acontecimientos de la comunidad, las manifestaciones tradicionales y las expresiones religiosas y políticas. Un segundo grupo de interacciones concurrentes son las funcionales - movimiento ${ }^{9}$, descanso y relajación ${ }^{10}$ y encuentros sociales- que se traslapan con las prácticas diarias ${ }^{11}$. En los espacios públicos de los barrios populares éstas son representadas por las actividades recreativas y comerciales que se realizan en parques y calles. Un tercer grupo de interacciones se relaciona con la construcción experiencial, emocional y cognitiva del espacio en términos de identidad del lugar ${ }^{12}$; pertenencia ${ }^{13}$; apropiación y territorialidad $^{14}$, y de control: "El control del espacio público es esencial en el equilibrio del poder en una sociedad particular"15. Todos ellos se pueden agrupar en usos simbólicos mediante

9 Carmona, y otros, 2003.

10 Carr, Francis y otros, 1992

11 Gehl, 1999.

12 Relph, 1976

13 Proshansky y otros, 1983.

14 Jiménez Domínguez, 2007; Bernardo y Palma-Oliveira, 2008.

15 Madanipour, 1999, p. 880. construcciones cognitivas ${ }^{16}$ y representaciones imaginarias ${ }^{17}$.

El artículo se basa en la investigación doctoral del autor $^{18}$, donde, desde una metodología cualitativa y usando casos de estudio de espacios públicos en barrios populares de Bogotá, se explora la relación de la gente con estos espacios, desde la perspectiva de la construcción social del espacio urbano. Se argumenta que existe una estrecha relación, y que esta relación contribuye a la transformación espacial del espacio, y a la construcción de identidad individual y colectiva de los habitantes. El texto se inicia con algunas precisiones con relación a los asentamientos populares y la especial naturaleza de los espacios públicos que allí se encuentran. Luego se explica la metodología usada para la investigación, para pasar a presentar los resultados de la investigación en términos de las construcciones cotidianas, funcionales y simbólicas en el espacio público de los barrios populares. El artículo cierra con una sección de conclusiones, que retoma ciertos aspectos tratados y proyecta la discusión en torno a la relación gente y lugar. 


\section{Asentamientos populares}

Antes de la revolución industrial, las prácticas de auto-gestión y auto-construcción eran las principales formas como las personas se proveían de vivienda. Con los desarrollos técnicos y el crecimiento de la economía, estas prácticas fueron dejadas a las personas más desfavorecidas y gradualmente desaparecieron de los procedimientos formales de la economía y la ciudad. Con la expansión urbana de las últimas cinco décadas, el fenómeno de la vivienda informal y los asentamientos informales o populares en general, ha crecido notablemente. En Latinoamérica más del 75\% de la población vivía en ciudades en 2001 y se estimaba que más del 30\% (128 millones de personas) de la población urbana del continente estaba viviendo en condiciones definidas por las Naciones Unidas para los asentamientos humanos como asentamientos informales ${ }^{19}$. Las cifras se incrementarán en el futuro cuando nuevas poblaciones urbanas requieran vivienda, servicios públicos y protección social.

Los asentamientos populares no sólo comprenden una gran porción de las ciudades latinoamericanas, sino que también son una parte dinámica de éstas, en términos físicos, sociales y culturales. Romero, Mesías y otros $^{20}$ explican cómo la producción de estos

19 UNCHS, 2003, p. 14.

20 Romero y otros, 2004, p. 29.

ARTíCULO: Construcción social de espacio público en barrios populares de Bogotá / Jaime Hernández García asentamientos está en manos de la gente, en lo que denominan "producción social de hábitat"; y que lejos de ser un problema, puede considerarse como una alternativa legítima. Igualmente como es la forma más extendida en América Latina que utiliza la gente para acceder a servicios urbanos y de vivienda. Fiori y Brandao ${ }^{21}$ argumentan que: "La informalidad urbana está entretejida inexorablemente con la ciudad como un todo -en todas las escalas y niveles- y puede también ser vista como otra vía de ser en la ciudad y construirla". Los asentamientos informales pueden también ser vistos como innovadores y creativos: "Hoy reconocemos el genio innovador de los hogares de bajos ingresos, que toman ventaja de las oportunidades culturales específicas para sobrevivir y mejorar sus condiciones de vida"22. En términos del espacio construido, estos entornos están sujetos a distintas interpretaciones: "Nosotros no creemos que 'informal' signifique in-forma (sin forma). Para nosotros implica que surge de sí mismo y de sus realizadores, cuya forma no ha sido reconocida aún, pero que está sujeta a reglas y procedimientos potencialmente tan específicos y necesarios como aquellos que han gobernado la construcción de ciudad oficial y formal"23. O en la asociación con arquitectura vernácula: “... los asentamientos espontáneos [informales], no menos que aquellos asentamientos tradicionales vernáculos tan ampliamente admirados, pueden enseñar mucho

21 Fiori y Brandao, 2010, p. 188.

22 AlSayyad, 1993, p. 5.

23 Brillembourg y Klumpner, 2010, p. 120.

revista invi № 78 / Agosto 2013 / Volumen № 28: 143-178 147 
FIGURA 1. ASENTAMIENTOS POPULARES EN BOGOTÁ. VISTA SOBRE LA PERIFERIA SUR OCCIDENTAL DE LA CIUDAD.

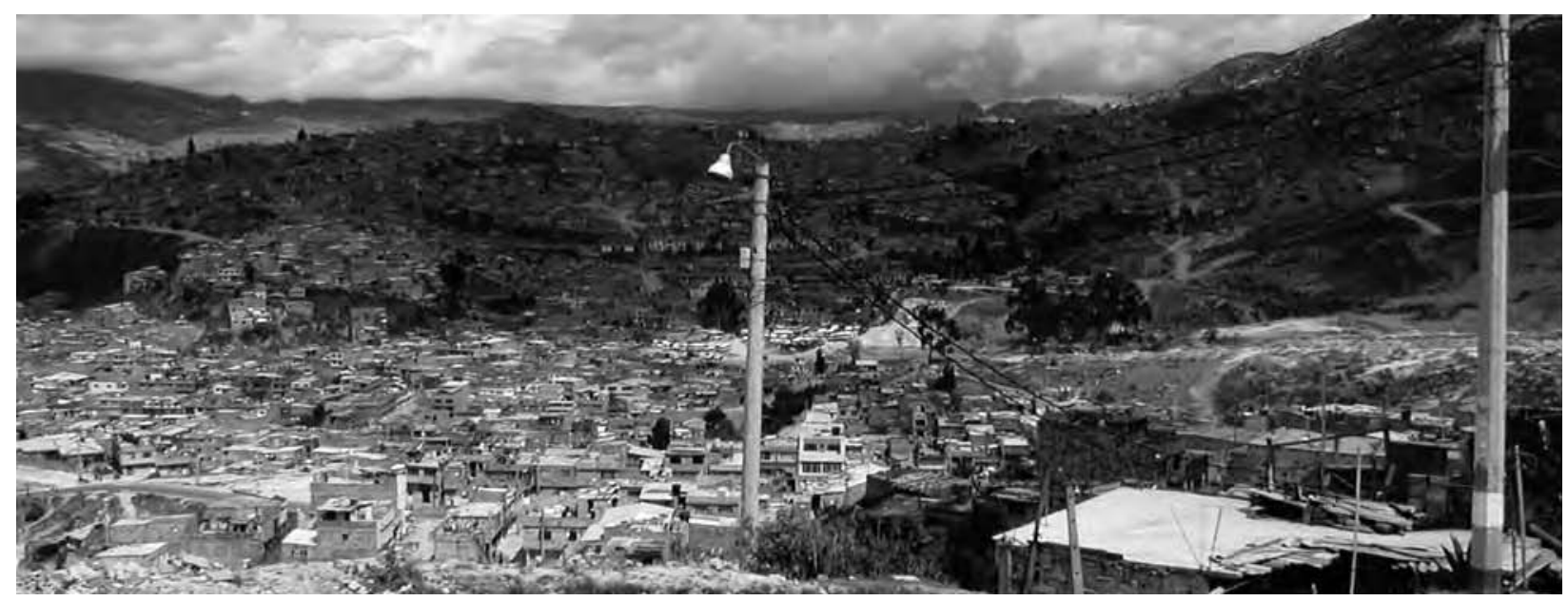

Foto del autor, 2005.

a los diseñadores" ${ }^{\prime 24}$, en los cuales los procedimientos de diseño y construcción enraizados en contextos locales pueden ser similares a los encontrados en asentamientos tradicionales ${ }^{25}$.

Los asentamientos populares son actualmente una parte muy importante de Bogotá (figura 1), no sólo en tamaño, sino también por el impacto urbano y social. No crecen al mismo ritmo que lo hacían en los años 60 s y 70 s, pero aún crecen más que el resto de la ciudad. Mas de la mitad de Bogotá se ha

24 Rapoport, 1988, p. 72-73.

25 Oliver, 2006.

148 revista invi № 78 / Agosto 2013 / Volumen No 28: 143-178 formado a partir de algún tipo de desarrollo informal o popular ${ }^{26}$. A pesar que se pueden encontrar sectores centrales con características informales, los barrios populares en Bogotá son sinónimo de periferias. Al igual que en la literatura internacional sobre el tema, en Colombia estos asentamientos tienden a definirse sólo a partir de lo que carecen: de infraestructura, de vivienda adecuada, de equipamientos, de servicios urbanos y de recursos económicos. Sin embargo, quizás la característica

26 Rueda García, 2000.

ARTíCULO: Construcción Social de Espacio Público en Barrios Populares de Bogotá / Jaime Hernández García 
principal es que estos lugares han crecido en gran medida a partir de las iniciativas y posibilidades de la gente y debido a las necesidades de vivienda y servicios urbanos requeridos, con poca participación de estamentos públicos o privados.

\section{Los espacios públicos en los barrios populares: la calle y la cancha}

El espacio público del barrio [popular] está conformado por el espacio exterior que rodea las viviendas, al cual tienen acceso diariamente las personas que viven alrededor. Es un espacio familiar, lleno de sentido para la comunidad, con valor simbólico para unos pocos; un lugar donde se reconocen las características particulares y las normas y valores específicos de grupos sociales determinados. Debido a su tamaño y escala, los espacios públicos del barrio son lugares para encontrarse con los demás cara a cara y llevar a cabo acciones orientadas por el afecto, el compromiso y la recreación ${ }^{27}$.

Los principales espacios públicos del barrio popular son la calle y el parque o cancha. Las calles pueden convertirse en escaleras, adaptándose a la topografía escarpada que encontramos en muchos

27 Segovia y Oviedo, 2000, p. 53.

ARTíCULO: Construcción social de espacio público en barrios populares de Bogotá / Jaime Hernández García de los barrios; el parque incluye la cancha (espacio deportivo) y otras áreas recreativas y, en ocasiones, espacios pavimentados y zonas verdes. Las grandes áreas pavimentadas encontradas en otras partes de la ciudad - conocidas como plazas heredadas de la época colonial - no existen en los barrios. La plaza "ha sido objeto de inspiración estética y controversia desde su inicio [...] Proporciona además un espacio físico, social y metafórico para el debate público sobre gobernabilidad, identidad cultural y ciudadanía ${ }^{28}$. Se podría decir que la plaza se ha transformado en el 'parque del barrio', con asociaciones y significados similares para los habitantes populares, como se discutirá más adelante.

Para Niño y Chaparro ${ }^{29}$, la calle es la unidad básica del espacio público en los barrios (figura 2). Las calles se utilizan para conectar, para realizar actividades comerciales y además para canalizar la mayoría de las expresiones sociales y culturales: "Por las calles fluye la vida urbana en los barrios; por ellas corre el amor, el odio, la felicidad, la tristeza y todas las fuerzas que mueven la vida de la gente del barrio"30. Las calles funcionan en estrecha relación con los espacios domésticos y comerciales cubiertos. Para Rojas y Guerrero ${ }^{31}$, la calle es la extensión de la casa; la frontera entre los espacios abiertos/cerrados o entre el exterior/interior

\footnotetext{
28 Low, 2000, p. 32-33.

29 Niño y Chaparro, 1997.

30 Ibíd., p. 6.
}

31 Rojas y Guerrero, 1997. 


\section{FIGURA 2. ESPACIOS PÚBLICOS EN ASENTAMIENTOS POPULARES EN BOGOTÁ, LA CALLE. BARRIO AGUAS CLARAS.}

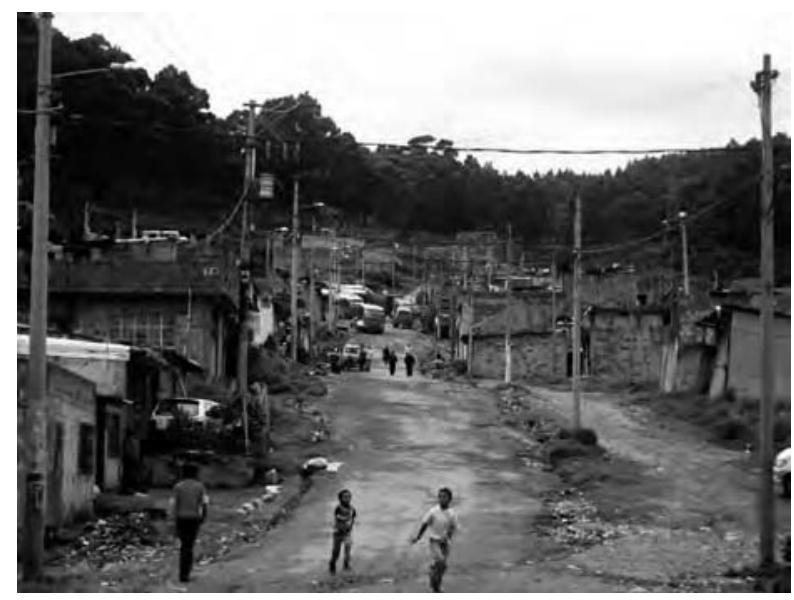

Foto del autor, 2008.

es una línea tenue. El parque del barrio o la cancha también son un espacio público reconocible (figura 3). En términos funcionales se orientan a los deportes y la recreación, pero su uso y significado van mucho más allá. Como sucede con las calles, tienen usos sociales y culturales además; la mayoría de ellos son un punto de referencia tanto físico como de identidad en los barrios ${ }^{32}$. Otra característica importante de los lugares abiertos/públicos en el barrio es la existencia de otros espacios

32 Niño y Chaparro, 1997.

150 revista invi № 78 / Agosto 2013 / Volumen No 28: 143-178
FIGURA 3. ESPACIOS PÚBLICOS EN ASENTAMIENTOS POPULARES EN BOGOTÁ, LA CANCHA. BARRIO EL DANUBIO.

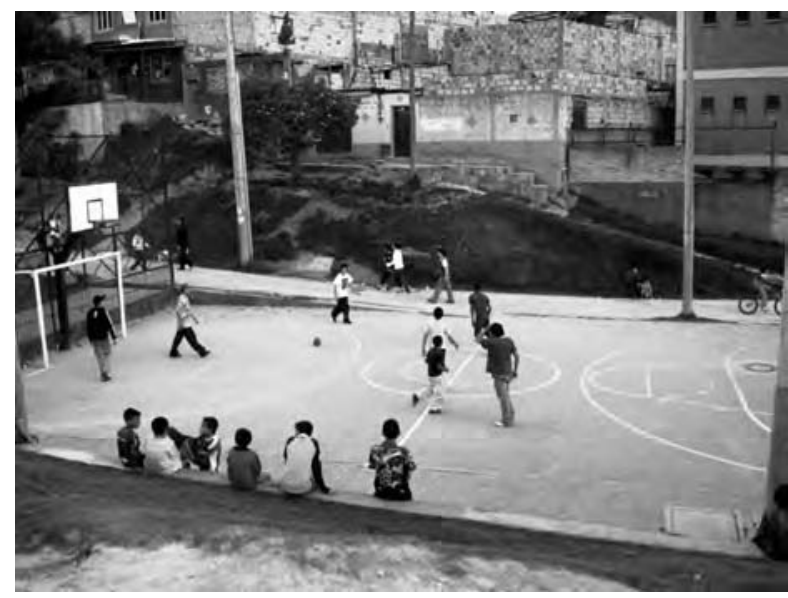

Foto del autor, 2008.

que no se ajustan al criterio de espacios urbanos públicos pero que, debido a su uso e importancia, están muy cerca de serlo. Carmona ${ }^{33}$ usa el término espacios terciarios o 'nuevas formas de espacio semipúblico' para referirse a los pequeños negocios (cafeterías y librerías, por ejemplo) donde la actividad pública fluye. En los barrios, dichos espacios están representados por los salones comunales y también por las tiendas, y más recientemente por los locales de servicio de Internet y los puestos de

33 Carmona, 2010.

ARTíCULO: Construcción Social de Espacio Público en Barrios Populares de Bogotá / Jaime Hernández García 
venta de minutos para llamadas a teléfono celular. Aunque en esta investigación no se discuten en detalle, se reconoce su importancia y relación con los espacios públicos.

Los espacios públicos en los barrios populares tienden a usarse más intensamente y exhiben dinámicas más significativas que aquellos en ambientes residenciales de clase alta, según lo observado por Riaño $0^{34}$ en los barrios de Ecuador y Colombia. Además, se caracterizan ampliamente por la recreación: "La recreación pasiva típica de los paisajes de la ciudad formal no es una prioridad en los contextos informales"35. Pero quizás la característica más importante es su estrecha relación con la gente que vive alrededor de ellos, lo cual confirma que estos espacios - aunque públicos en términos de accesibilidad y propiedad- pueden no serlo tanto en términos de uso y apropiación. Los siguientes apartados de este artículo pretenden demostrar lo anterior.

\section{Metodología}

El trabajo recoge parte de la investigación doctoral del autor, y en este sentido la metodología que aquí se presenta cubre el conjunto general de la investigación aunque para esta sección del trabajo

34 Riaño, 1990.

35 Beardsley y Werthmann, 2008, p. 33. y el presente artículo algunos apartados de la misma son más sobresalientes que otros, en especial el trabajo realizado en los 6 casos de estudio particulares.

La investigación está basada en 57 casos generales de estudio de espacio público en barrios populares de Bogotá, tomados entre los años 2003 al 2007 (tabla 1). Seis casos particulares fueron seleccionados para hacer una profundización de campo en los años 2008 y 2009. Se empleó una metodología cualitativa, y se usaron los siguientes métodos para recoger la información: entrevistas, observación, mapeo y documentos visuales y de texto.

Cuatro distintas clases de entrevistas se realizaron: semi-estructuradas con actores claves de las comunidades, abiertas con los residentes, abiertas con actores claves del gobierno municipal y académicos, y conversaciones casuales con usuarios de los espacios públicos. Se realizaron 29 entrevistas semi-estructuradas y 47 abiertas. Los actores clave fueron identificados en cada caso, entre ellos miembros pasados y actuales de las $\mathrm{JACs}^{36}$, quienes jugaron un papel preponderante en la producción del espacio público, fundadores o primeros pobladores de los barrios, y personas que tuvieron o tienen un interés especial por el espacio público por tener, por ejemplo, un negocio (tienda) en él.

36 JACs: Juntas de Acción Comunal. Organizaciones comunitarias de barrio con personaría jurídica, que les permite establecer relaciones con el gobierno municipal.

revista invi № 78 / Agosto 2013 / Volumen № 28: 143-178 151 
TABLA 1. LOS 57 CASOS GENERALES DE ESTUDIO.

\begin{tabular}{|c|c|c|c|}
\hline Caso No. & Nombre & Caso No. & Nombre \\
\hline 1 & Calle peatonal Costa Rica & 30 & Parque Luis Park \\
\hline 2 & Parque La Paitana: 'Sueños de Vida' & 31 & Parque Olivares: 'Nuestro Parque' \\
\hline 3 & Parque Garcés Navas: 'Senderos de Vida' & 32 & Parque Lorenzo Alcantus \\
\hline 4 & Parque Los Monjes & 33 & Parque La Marichuela \\
\hline 5 & Calle-escalera: 'El Codito' & 34 & Parque Usminia \\
\hline 6 & $\begin{array}{l}\text { Calle-escalera Santa Cecilia: 'Ascenso y } \\
\text { Descenso con Seguridad' }\end{array}$ & 35 & Parque Tequendama \\
\hline 7 & Parque San Francisco: 'Jardín Abuelos' & 36 & Parque Quintas del Plan Social \\
\hline 8 & Parque Pensilvania & 37 & Parque Quintas del Plan Social II \\
\hline 9 & Calle-escalera: La Reconquista & 38 & Parque Aurora II \\
\hline 10 & Parque Molinos & 39 & Parque Aurora \\
\hline 11 & Calle-escalera: San Agustín & $40^{*}$ & Parque Danubio \\
\hline 12 & Calle peatonal Rafael Uribe & 41 & Parque San Isidro \\
\hline 13 & Parque El Cerrito & 42 & Parque Usme Centro \\
\hline 14 & Parque Asovivir & 43 & Parque Nuevo Porvenir: 'La Reconciliación' \\
\hline $15^{*}$ & Parque Villa Sonia: 'Por un Bien Común' & 44 & Calle-escalera La Castaña \\
\hline 16 & Parque Bosa Brasilia & 45 & $\begin{array}{l}\text { Calle peatonal San Martín de Loba: 'Alameda el } \\
\text { Progreso' }\end{array}$ \\
\hline 17 & Calle peatonal San Martín & 46 & 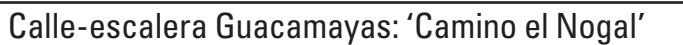 \\
\hline 18 & Parque Américas & 47 & Calle-escalera Bello Horizonte: 'Calle de la Unión' \\
\hline 19 & Parque Bellavista & $48^{*}$ & Parque Aguas Claras \\
\hline 20 & Parque Bohios de Hunza & $49^{*}$ & Parque Nueva Argentina \\
\hline 21 & Parque La Aldea & 50 & Parque Nueva Argentina II \\
\hline $22^{*}$ & Parques La Andrea & $51^{*}$ & Parque Manuela Beltrán: Los Cerezos \\
\hline 23 & Parque Brasilia & 52 & Parque Rincón de Galicia \\
\hline 24 & Parque La Marichuela II & 53 & Parque Estrella del Sur: 'La Conexión' \\
\hline 25 & Chuniza park & 54 & Tanque Laguna Park \\
\hline 26 & El Líbano park & 55 & El Consuelo boulevard and stairways \\
\hline 27 & Gran Yomasa park & 56 & San Carlos Park: 'El Planchón' \\
\hline 28 & Valle de Cafam park & 57 & Restrepo Park \\
\hline 29 & $\begin{array}{l}\text { Libano pedestrian street: 'Alameda Tercer } \\
\text { Milenio' }\end{array}$ & & \\
\hline
\end{tabular}

Los indicados con asterisco $\left(^{*}\right)$ corresponden a los 6 casos de estudio particulares 

Cincuenta y tres observaciones fueron registradas en mapas (tabla 2), cubriendo el uso de los espacios públicos en días entre semana y los fines de semana, así como en las mañanas, tardes y noches. Algunas de estas observaciones fueron intencionalmente programadas para coincidir con eventos en los barrios, como partidos de fútbol, reuniones comunitarias o concentraciones de carácter político o religioso. En todas las observaciones se pretendieron identificar el tipo y la calidad de la interacción de los usuarios con los espacios públicos.

Los documentos visuales y escritos tuvieron como objetivo complementar y ayudar a comprender lo recogido por las entrevistas y las observaciones. Lo visual incluyó fotos de los espacios públicos, fotos aéreas, mapas y foto evocación; mientras que lo escrito contempló el estudio de políticas urbanas y de espacio público en Bogotá, reportes pertinentes y programas municipales. También se consultaron artículos de la prensa local y medios informativos impresos de las comunidades en los barrios.

Para el análisis de la información recogida, se siguió la técnica propuesta por Miles y Huberman ${ }^{37}$ para metodologías cualitativas: reducción de la información, visualización de la información, identificación de temas comunes, codificación de los mismos, conclusiones preliminares y verificación de las mismas. Una lista de las principales

37 Miles y Huberman, 1994. características de cada uno de los seis casos se produjo para hacer comparaciones iniciales entre sí, verificación con información de los 57 casos generales y elaboración de las primeras interpretaciones cruzándolas con las teorías y conceptos estudiados. Las características fueron gradualmente convirtiéndose en patrones y luego en categorías, para una exploración y análisis más profundo. Sobre éstas se construyeron los argumentos de la investigación.

\section{Construcción social cotidiana: Prácticas sociales y culturales}

\section{RELACIONES SOCIALES}

Los 57 casos de estudio muestran que el uso inicial y principal de los espacios públicos en los barrios populares tiene relación con la casa. La puerta es el primer punto de contacto entre el mundo cerrado e interior del hogar y el mundo abierto y exterior del espacio público. La investigación encontró que no es poco frecuente en los asentamientos populares encontrar la puerta abierta para ver pasar a la gente, esperar a alguien con quien charlar o vigilar a los niños mientras juegan en la calle, a pesar de 
los aparentes problemas de seguridad que se escuchan. La puerta es el primer punto de contacto con el exterior pero no el único; las ventanas, los balcones y las terrazas desempeñan cada uno su papel. Los casos generales muestran que el uso de las calles y los parques en los barrios tiende a ser específico según el género, la edad y el tiempo. Las mujeres son las principales usuarias durante los días hábiles, como lo explican Rojas y Guerrero ${ }^{38}$ : "Las mujeres usan la calle para ir a la tienda, para ir a trabajar, para llevar a los niños a la escuela o al parque; pero también la usan para charlar con sus amigos, para enterarse de las 'últimas noticias' del barrio, para mostrarse, para coquetear [...]". Por otro lado, los niños son los principales actores en la tarde y al anochecer; durante las noches y los fines de semana, los hombres y los adultos jóvenes asumen el control. Entre los usos que se les dan a los espacios públicos están: hacer compras, reunirse y hablar con los vecinos, jugar y conversar con los amigos, jugar fútbol o baloncesto, charlar y beber. Estas actividades muestran las tendencias de las prácticas diarias relacionadas con los espacios públicos. No obstante, se podría decir que cada caso es diferente, lo cual confirma la diversidad de los asentamientos populares.

Las calles no sólo están diseñadas para caminar e ir de un lugar a otro, como afirma Gehl' ${ }^{39}$ :

38 Rojas y Guerrero, 1997, p. 26.

39

Gehl, 1999, p. 258
"Caminar, ciertamente, es más que una manera de desplazarse; también es un proceso social en el que constantemente encontramos, vemos y escuchamos a otras personas, y es una actividad de la cual podemos pasar a otras sin pensarlo". En el barrio El Danubio, por ejemplo, podría decirse que la calle principal es el lugar donde 'ocurre todo'. Es el lugar del transporte, las compras, los encuentros y el entretenimiento. Probablemente en algún momento del día la mayoría de las personas llegarán a la calle principal por alguna razón: para tomar el autobús, comprar algo, encontrarse con alguien o tomarse un par de cervezas con los amigos. Se puede observar hombres, adultos jóvenes y a veces mujeres disfrutando de una cerveza; la compran en la tienda y, si el clima lo permite, llevan una silla (o una banca) de la tienda hasta el área pavimentada para beber allí y charlar afuera con los amigos. El consumo de cerveza y los espacios públicos están estrechamente relacionados, se podría decir que son una manifestación típica y particular (aunque no exclusiva) de los barrios populares.

El "parque del barrio" muestra muchas de las mismas actividades sociales cotidianas observadas en las calles, con algunas diferencias. Aquí no se observan aquellas relacionadas con el transporte, a menos que haya un paradero de buses cerca del parque (como en el barrio Nueva Argentina); los 
encuentros y la conversación son más frecuentes, pero los niños y los adultos jóvenes son los usuarios principales de estos lugares. En el parque de Los Cerezos, por ejemplo, las principales actividades observadas son jugar, reunirse y charlar, pero los actores principales suelen ser mujeres y niños. Las madres llevan a sus bebés al parque para tomar el sol, el aire o sólo para caminar un poco. Los niños pequeños juegan en el parque, generalmente bajo la supervisión directa de sus madres. Mientras cuidan a sus bebés y niños pequeños, las mujeres hablan entre sí en las pocas bancas del parque o simplemente se sientan en el pasto. Sin embargo, en las tardes y los fines de semana la escena es distinta; los actores principales del parque tienden a ser niños un poco mayores y adolescentes. Otra actividad de encuentro y charla observada en el parque se centra en las parejas de novios que encuentran en el parque un lugar apropiado para estar juntos. Generalmente los jóvenes que conforman estas parejas son antiguos miembros de los grupos de juego de años anteriores, según los hallazgos de Rojas y Guerrero ${ }^{40}$ para su investigación. El parque es un buen lugar para reunirse: "Veámonos en el parque y luego decidimos qué hacer" es una propuesta común. Ayuda el hecho de que

40 Rojas y Guerrero, 1997. el paradero de autobús no está lejos del parque, de modo que la gente se encuentra allí de camino hacia el paradero. Las fronteras del parque también son importantes, ya que pueden ser puntos de encuentro y contribuyen a crear la atmósfera del lugar, tanto social como físicamente. Por ejemplo, las tiendas o ciertos lugares "especiales" en Los Cerezos, como la miscelánea de don José (figura 4) o la casa de Luis Emilio (figura 5), son significativos. Según Tito (residente de Los Cerezos), la miscelánea es famosa por los helados caseros y la casa de Luis Emilio, por su fachada azul brillante. En este sentido, Rojas y Guerrero ${ }^{41}$ afirman que las direcciones no son importantes (y muy confusas) en los asentamientos populares; en su lugar, la gente usa señales (como la miscelánea o la casa de Luis Emilio) para dar direcciones. Al hacerlo, construyen significado y le dan identidad a sus barrios ${ }^{42}$.

Las actividades sociales cotidianas que se desarrollan en los espacios públicos contribuyen a darle forma a esos lugares en términos de cómo se usan y cómo se transforman a través de ese uso. Las relaciones sociales se construyen en las calles y los parques; sus esquinas y fronteras adquieren 'nuevos' usos y la transformación real del espacio se

41 Ibid.

42 De esta manera se identifica inmediatamente al intruso: no conoce los códigos. En mi caso, cuando fui a hacer una entrevista me dijeron que buscara la casa de Luis Emilio, la de la fachada azul, y que cerca de allí encontraría la casa que buscaba. Después de preguntar en varias tiendas, finalmente encontré la casa. 
FIGURA 4. PAROUE DE LOS CEREZOS Y SUS ALREDEDORES EN EL BARRIO MANUELA BELTRÁN. LA MISCELÁNEA DE DON JOSÉ (ESOUINA).

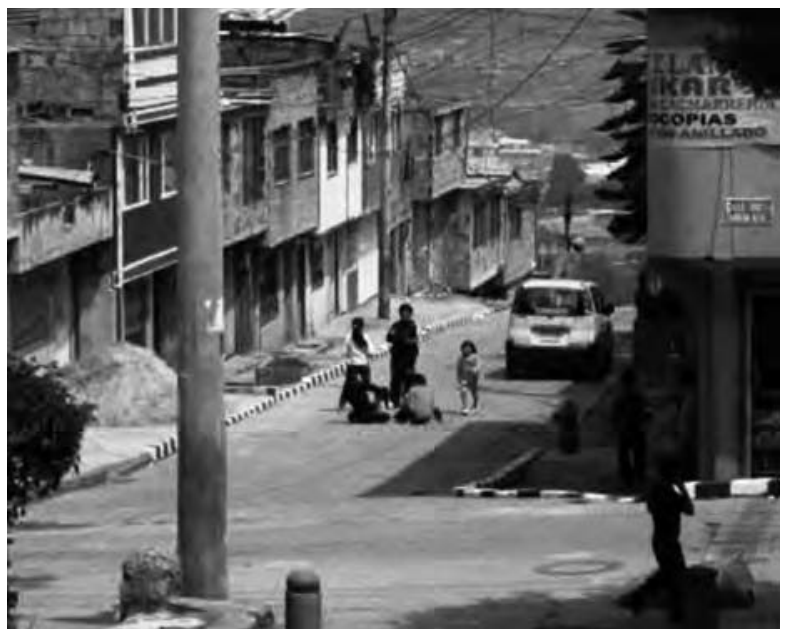

Foto del autor, 2008

observa cuando, por ejemplo, un bebedor de cerveza lleva una silla a la calle o cuando se construye un jardín frente a una casa. Pero estas actividades de consumo también ayudan a construir una red de conexiones con el lugar, como Carr, Francis y otros $^{43}$ sostienen: "Asumiendo que existe un cierto grado de relevancia o de congruencia entre los lugares y sus usuarios, el uso puede crear conexiones simbólicas".

43 Carry otros, 1992, p. 193.

\section{FIGURA 5. PAROUE DE LOS CEREZOS Y SUS ALREDEDORES EN EL BARRIO MANUELA BELTRÁN. LA CASA DE LUIS EMILIO, BARRIO EL DANUBIO.}

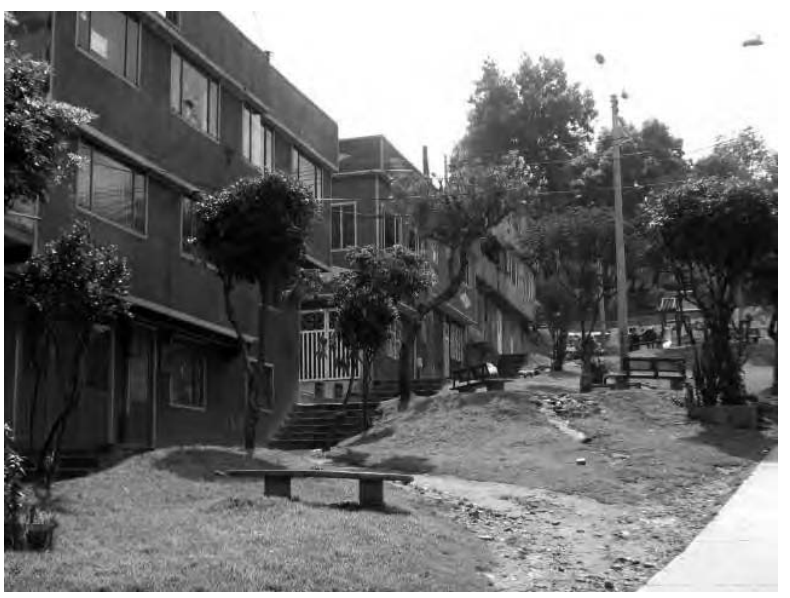

Foto del autor, 2008

\section{EXPRESIONES CULTURALES}

Según lo expone $\mathrm{Low}^{44}$, los lugares adquieren la forma que les dan las expresiones ideológicas, políticas, tecnológicas y culturales de quienes interactúan con ellos. Las prácticas culturales que se dan alrededor de los espacios públicos en los asentamientos populares contribuyen a la construcción social y la forma que van tomando estos espacios.

44 Low, 1996.

revista invi № 78 / Agosto 2013 / Volumen №28: 143-178 157 
Entendemos por cultura las visiones, creencias, valores y tradiciones de los grupos sociales ${ }^{45}$ que ayudan a "definir el entorno para que se ajuste a su forma de vida y le sirva de apoyo" ${ }^{\prime 46}$. En los estudios de caso se hallaron muchas expresiones culturales que, para el propósito de nuestro análisis, se pueden agrupar en cinco temas (algunas de ellas también se pueden ver como expresiones sociales): celebraciones, comida y bebida, juegos tradicionales, creencias religiosas, y actividades comunitarias y políticas.

\section{Celebraciones}

La evidencia recogida de los seis estudios de casos muestra que las calles y los parques son considerados buenos lugares para reunirse y celebrar. Estas actividades van desde reuniones informales con los amigos hasta celebraciones más elaboradas con grandes grupos de gente (incluso toda la comunidad). Las reuniones pequeñas con los amigos, donde hay charla, bebida, música y a veces baile, son muy comunes, especialmente en los fines de semana. En el barrio La Andrea, por ejemplo, un grupo de hombres llevan sillas de sus casas hasta el parque, dejan la puerta abierta para que puedan oír la música de su equipo de sonido, y entran y salen con implementos de cocina (figura 6). Pasan así

45 Rapoport, 1976.

$46 \quad$ Kellett, 1995, p. 52.

158 revista invi № 78 / Agosto 2013 / Volumen No 28: 143-178

\section{FIGURA 6. REUNIÓN INFORMAL DE VECINOS EN EL BARRIO LA ANDREA.}

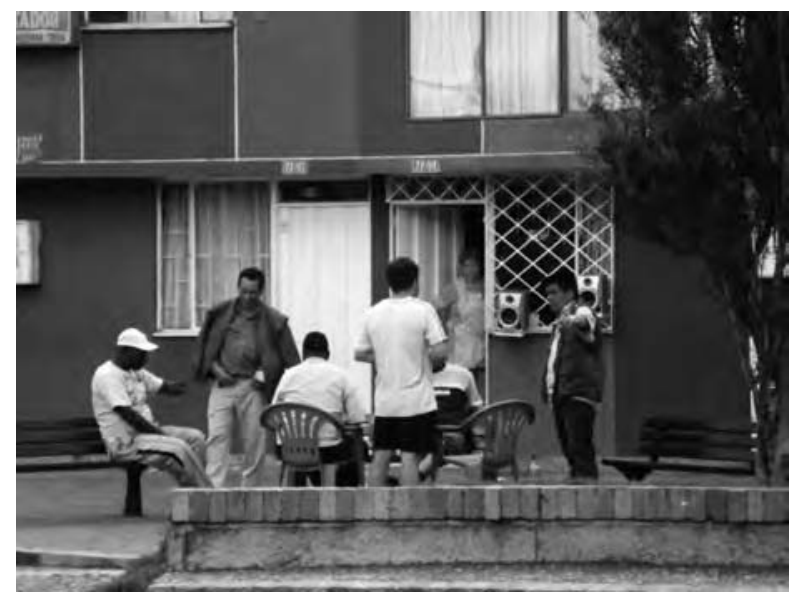

Foto del autor, 2008.

la tarde y las mujeres también se suman a la reunión de vez en cuando, mientras los niños están por ahí, jugando en el parque.

Las celebraciones más importantes se llevan a cabo generalmente durante Navidad y Pascua, en una mezcla de expresiones sociales y tradiciones religiosas. Rojas y Guerrero ${ }^{47}$ encontraron en su investigación que las comunidades se organizan para recolectar dinero para pintar la fachada de las

47 Rojas y Guerrero, 1997.

ARTíCULO: Construcción Social de Espacio Público en Barrios Populares de Bogotá / Jaime Hernández García 
FIGURA 7. ANFITEATRO PROMOVIDO ESPECIALMENTE POR LA COMUNIDAD DEL BARRIO LA ANDREA PARA REUNIONES.

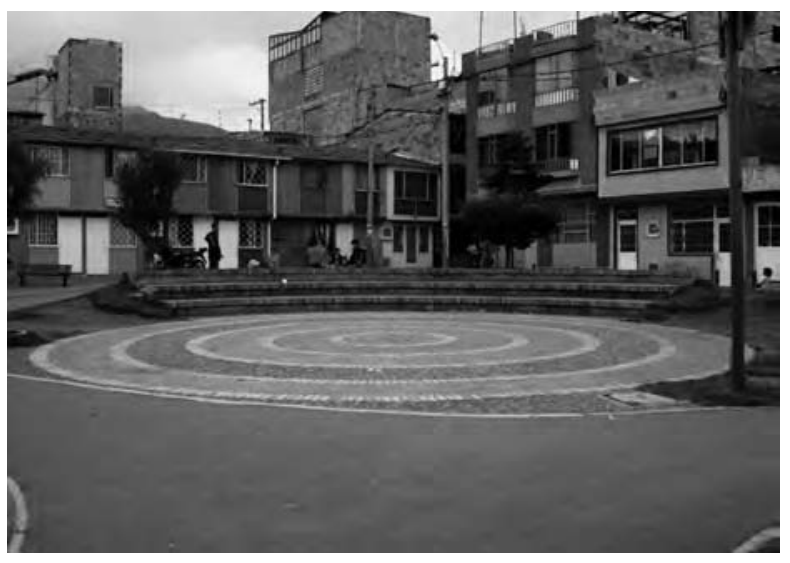

Foto del autor, 2008

casas, pavimentar las calles, decorarlas con adornos navideños y organizar fiestas.

\section{Comida y BeBida}

A las celebraciones y manifestaciones culturales importantes hechas en los espacios públicos de los barrios se asocian el comer y beber. El barrio La Andrea nos da un ejemplo explícito de cómo estas actividades dan forma a los espacios públicos. En el proceso participativo de diseño del parque 'El Ocho' había
FIGURA 8. CANCHA DE TEJO EN EL BARRIO AGUAS CLARAS.

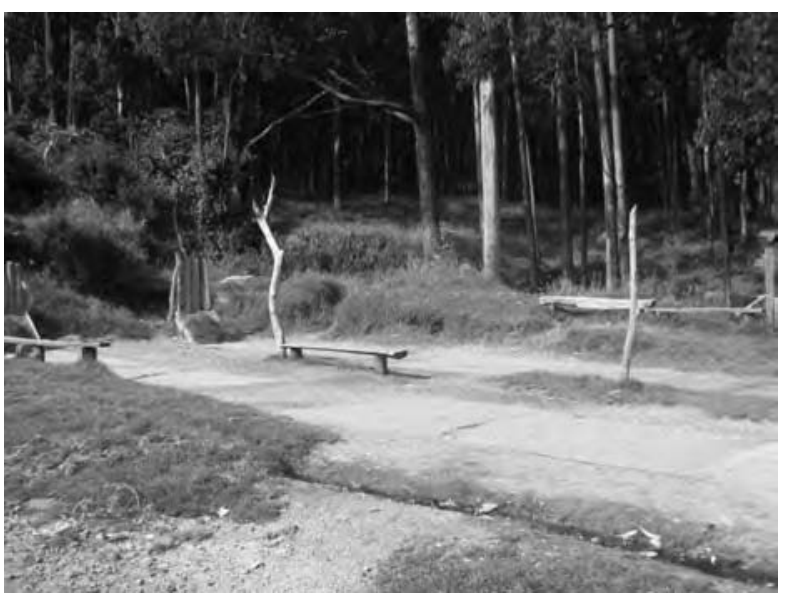

Foto del autor, 2008.

un lugar particularmente aglutinados (figura 7): "Era muy importante para nosotros tener un espacio redondo [anfiteatro] dentro del parque para hacer nuestra olla comunitaria" (entrevista con Martha, residente de La Andrea, diciembre de 2008). La 'olla comunitaria' es un evento que se celebra mensualmente (o cuando sea necesario), en el que quienes viven cerca del parque se reúnen para cocinar, comer y beber. Además escuchan música y eventualmente bailan, según dice Martha. La mayoría de las veces, la comida es una 
sopa llamada sancocho ${ }^{48}$ (de allí el nombre de 'olla'). Este barrio es particularmente conocido por su comida; los tamales y la lechona son famosos en la zona ${ }^{49}$ y no es raro en los fines de semana observar a la gente compartiendo estos platos en la calle o en el parque, acompañados de cerveza.

\section{Juegos tradicionales}

Hay una serie de juegos relacionados con los espacios públicos que pueden ser considerados manifestaciones culturales ${ }^{50}$. Son relativamente comunes en los asentamientos populares y poco frecuentes en el resto de la ciudad. El tejo $0^{51}$ es el mejor ejemplo. Se puede jugar en un espacio abierto, según lo observado en el barrio Aguas Claras (figura 8), o en uno cerrado, pero siempre tiene relación con el espacio público en frente. Es un juego rural tradicional del centro del país y como algunos autores sostienen ${ }^{52}$, guarda una relación con el pasado rural de las comunidades. Otro jue-

48 Plato tradicional que se prepara en casi todo el país con algunas diferencias regionales; es una sopa cuyos ingredientes incluyen 'todo': papa, plátano, yuca, carne, pollo y verduras.

49 'Tamales': masa de maíz rellena de pollo y/o carne; 'lechona': lechón relleno de arroz y verduras. Son dos platos tradicionales de la región centro-occidental de Colombia (regiones de Huila y Tolima), que también dan una idea de los orígenes de algunos de los residentes del barrio.

50 Niño y Chaparro, 1997.

51 Actividad grupal que consiste en arrojar un disco de metal del tamaño de un puño desde una distancia de 20 a 30 metros para intentar golpear una mecha y hacerla estallar.

52 García Canclini, 1989; Niño y Chaparro, 1997; Rojas y Guerrero, 1997. go tradicional es la rana ${ }^{53}$, pero ésta debe jugarse en un espacio cerrado o bajo cubierta; al igual que el tejo, generalmente se extiende al espacio público. En estos dos juegos participan principalmente hombres, sin embargo, algunas veces se ven mujeres jugando. La música y la cerveza son parte de la diversión en ambos juegos y a veces también hay comida y baile. Al igual que en otras actividades desarrolladas en espacios públicos que incluyen licor, se pueden presentar conflictos.

\section{Creencias religiosas}

En los espacios públicos en los asentamientos populares también se observan manifestaciones religiosas. Los estudios de caso muestran tres tipos de uso religioso además de las celebraciones socioreligiosas de Navidad y Pascua mencionadas anteriormente: en primer lugar, el templo situado en la calle principal o frente al parque y su interacción con el espacio público (en el barrio Tanque Laguna

53 Anillos metálicos que se lanzan desde cierta distancia con el objetivo de meterlos en la boca de una rana también metálica.

ARTíCULO: Construcción Social de Espacio Público en Barrios Populares de Bogotá / Jaime Hernández García 
FIGURA 9. IGLESIA CATÓLICA EN EL PARQUECANCHA DEL BARRIO TANOUE LAGUNA.

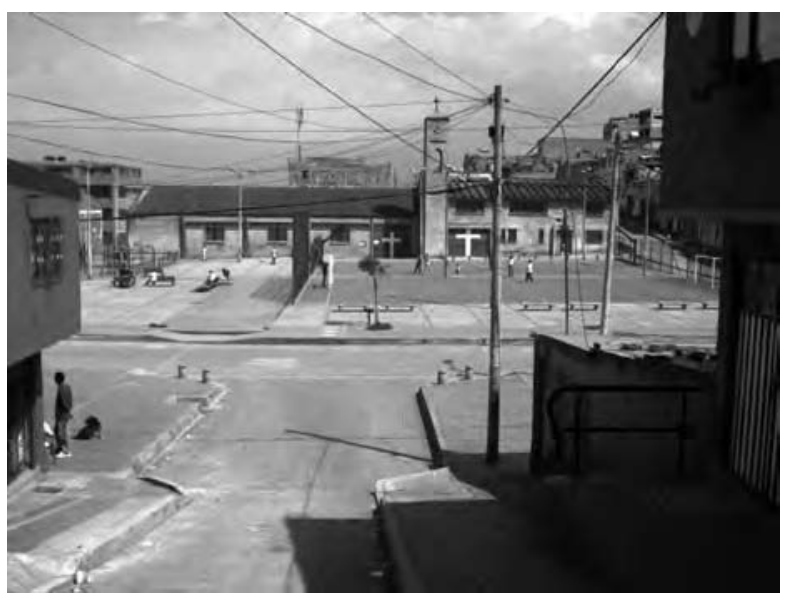

Foto del autor, 2008

por ejemplo, figura 9); segundo, la ermita en el parque (El Danubio); y en tercer lugar, las imágenes religiosas en la fachada de las casas (Los Cerezos).

En los 57 casos estudiados para esta investigación, había al menos un templo católico en cada barrio. En la mayoría había también una o más sedes de otras creencias religiosas. La ubicación del templo católico en el barrio emula, en lo posible, la localización de las iglesias en la zona

ARTíCULO: Construcción social de espacio público en barrios populares de Bogotá / Jaime Hernández García

\section{FIGURA 10. EVENTO CULTURAL EN EL PAROUE - CANCHA DEL BARRIO LA ANDREA.}

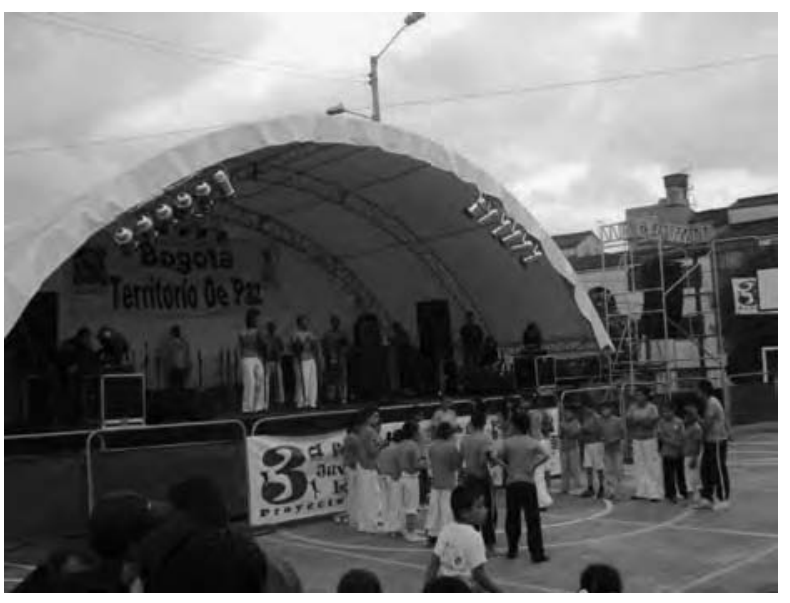

Foto del autor, 2008

central de la ciudad: por lo general en el marco de las plazas para resaltar su importancia ${ }^{54}$. Las ermitas y especialmente las imágenes religiosas en la fachada de las casas son comunes en los barrios. Para Hernández Bonilla ${ }^{55}$, las ermitas son no sólo expresiones de fe religiosa sino también el resultado de acciones cotidianas de uso y apropiación. Rojas y Guerrero ${ }^{56}$ afirman que las imágenes religiosas son importantes debido a su valor histórico, cultural y de identidad.

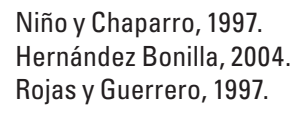

revista invi № 78 / Agosto 2013 / Volumen № 28: 143-178 161 


\section{ACTIVIDADES COMUNITARIAS Y POLÍTICAS}

Muchos autores reconocen la dimensión política de los espacios públicos ${ }^{57}$. Son importantes en las actividades participativas (figura 10) de la comunidad, y el activismo político ayuda a construir democracia y gobernabilidad. En los barrios se observan actividades relacionadas con la comunidad y la política - la mayoría de ellas organizadas por la JACs-, especialmente en el parque-cancha y el salón comunal.

En el barrio El Danubio, Arturo, el presidente de la JAC, habló abiertamente en la entrevista que se le hizo en diciembre de 2008 sobre una reunión que tuvieron en el parque-cancha para distribuir algunos títulos de propiedad entre las familias: "Nos toca 'trabajar' con el político de turno, jugamos su juego para conseguir lo que necesitamos para el barrio". Se invitó a concejales y ediles a que repartieran títulos de propiedad con un interés político evidente: ganar adeptos para las siguientes elecciones. Dos elementos más lo confirman: el salón comunal y el altavoz que hay en algunos barrios. El salón comunal es administrado por la JAC y se utiliza sobre todo para actividades políticas y de la comunidad. Aunque es un espacio cerrado, su uso es bastante público y se considera un espacio público del barrio. La JAC también controla el altavoz, un elemento curioso encontrado en muchos barrios.

57 Niño y Chaparro, 1997; Carmona y otros, 2003; Madanipour, 2003; Páramo y Cuervo Prados, 2006.

\section{Construcción social funcional: Recreación y Comercio}

\section{EL ESPACIO PÚBLICO COMO LUGAR DE JUEGO}

En los barrios, los usos 'obligatorios' de los espacios públicos — según lo explica Gehl ${ }^{58}$ —, como rutas de paso por ejemplo, guardan relación con las acciones funcionales pero 'opcionales': "Estas actividades solamente se dan cuando las condiciones exteriores son óptimas, cuando el clima y el lugar las permiten". Entre estas actividades de barrio, la más visible es la recreación activa que también se puede ver como una actividad social y cultural. En los barrios populares, el espacio público y la zona de juego son sinónimos, lo cual refuerza los argumentos de Beardsley y Werthmann $^{59}$. Los 57 casos explorados para esta investigación muestran evidencia de ello, pues más de la mitad de los espacios públicos son campos deportivos y casi todos tienen zona de juego. Pero el juego no es una actividad confinada a los parques; las calles son quizás el lugar más común: "Los niños tienden a jugar más en las calles, en las zonas de parqueo y a la entrada de sus casas que en las zonas de juego diseñadas para ese propósito"

58 Gehl, 1987, p. 13

59 Beardsley y Werthmann, 2008

60 Gehl, 1987, p. 27. 
Las calles son el espacio de juego primario y más asequible para los niños del barrio. Puesto que la casa es limitada en términos de espacio y oportunidades sociales, los niños prefieren estar en la calle con sus amigos. "Los niños más pequeños juegan fútbol, montan bicicleta o sacan sus juguetes a la calle; en la mayoría de los casos, quienes cuidan de ellos son sus hermanos mayores o la gallada a la cual pertenecen" ${ }^{\prime 61}$. Los menores también son supervisados por sus madres, quienes los miran desde la ventana o la puerta de la casa.

Para los adolescentes, las calles son su segundo hogar: "La casa es aburrida, es como estar en una 'cárcel'; la libertad está en la calle, ese lugar es para compartir con los amigos y expresarse; la calle es el sitio de la diversión"62. Los seis estudios de caso lo confirman: las calles son para jugar. Sin importar si están destrozadas, como en Aguas Claras o en Villa Sonia, o si tienen forma de escalera debido a la topografía, como en Tanque Laguna, los niños juegan allí. A través del juego, los niños y jóvenes se conectan con otras actividades sociales y culturales dentro del barrio y su comunidad, y desarrollan maneras de apropiarse del espacio y construir identidad. Los jóvenes buscan 'su' espacio en las calles, esquinas y parques. Sin embargo, este proceso no siempre está libre de conflicto.

61 Rojas y Guerrero, 1997, p. 23.

62 Ibíd, p. 24.

ARTíCULO: Construcción social de espacio público en barrios populares de Bogotá / Jaime Hernández García
En términos funcionales, los parques del barrio están destinados al juego y los deportes. Usualmente tienen una o más canchas multifuncionales (como en El Danubio) para jugar basquet, micro fútbol o voleibol (figura 11) y varias zonas de juegos con estructuras metálicas o de madera. El resto del parque está pavimentado o tiene zonas verdes también adecuadas para jugar. Al igual que en las calles, jugar en el parque es una actividad social que conecta a los participantes con otras personas; no obstante, los actores de los parques difieren un poco de los usuarios de la calle. Por lo general no se ven niños pequeños, a menos que vayan acompañados por sus madres; los usuarios adultos suelen hacerse presentes en grandes cantidades durante los fines de semana. Pero los usuarios principales y cotidianos de estos espacios parecen ser los adultos jóvenes. Una de las principales actividades que se desarrollan en los parques son los partidos de micro fútbol. Después de que termina el partido comienza la celebración (sin importar cuál haya sido el resultado), que incluye cerveza, música y a veces baile y comida. También se construyen relaciones sociales y en ocasiones surgen conflictos. Las prácticas sociales y culturales se desarrollan alrededor de la actividad deportiva, lo cual contribuye a generar relaciones con el espacio y a transformarlo. 


\section{FIGURA 11. JUEGO DE MICRO-FÚTBOL EN EL PAROUE DEL BARRIO EL DANUBIO.}

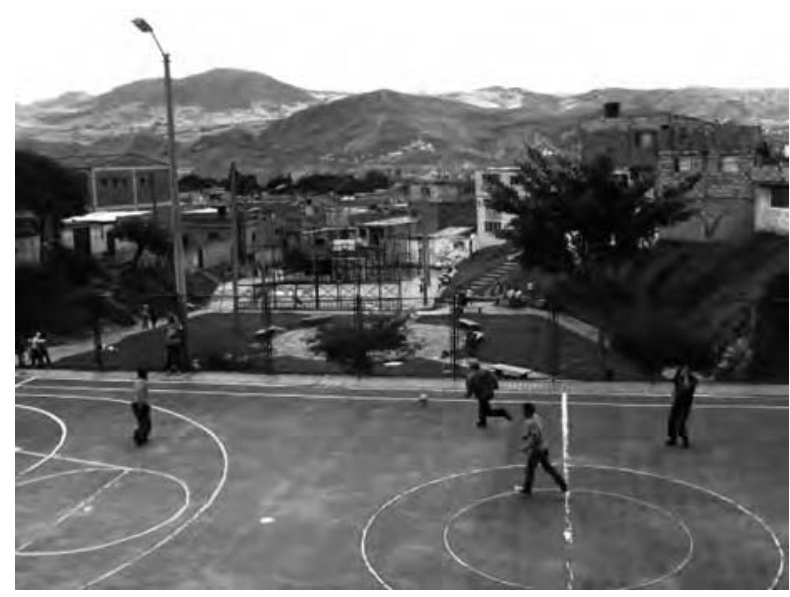

Foto del autor, 2008

\section{ACTIVIDADES COMERCIALES}

En términos de función, los espacios públicos de los barrios también significan comercio. La recreación es tal vez el uso más visible de estos espacios, pero el comercio está aumentando significativamente. El comercio es una tendencia extendida en los espacios públicos en general, como lo confirma Carmona ${ }^{63}$ : "... siempre ha habido una fuerte relación entre comercio y espacio público urbano...". En los espacios públicos de los barrios también es

63 Carmona, 2010, p. 145.
FIGURA 12. PANADERÍA EN EL BARRIO MANUELA BELTRÁN.

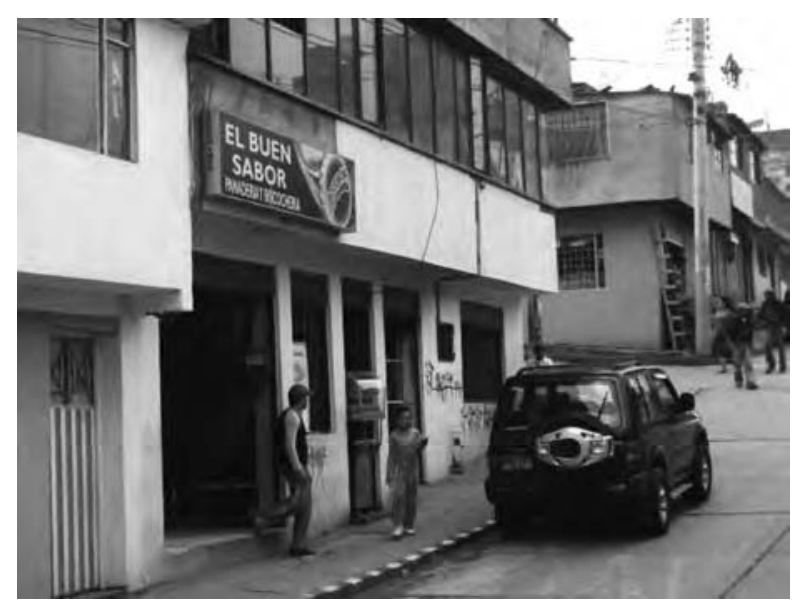

Foto del autor, 2008

característico ver actividades comerciales; se podría decir que ellas no sólo cumplen una función económica sino que también son manifestaciones sociales constructoras de cultura. Las actividades comerciales que se dan en los espacios públicos se pueden dividir en dos tipos: las que se dan en los locales que de alguna manera tienen relación con las calles y los parques; y las que ocurren en los espacios públicos propiamente dichos. En el primer tipo, la tienda y sus variaciones es la principal manifestación comercial; del segundo, las ventas

ARTíCULO: Construcción Social de Espacio Público en Barrios Populares de Bogotá / Jaime Hernández García 
FIGURA 13. "TIENDA DE MINUTOS" EN EL BARRIO MANUELA BELTRÁN.

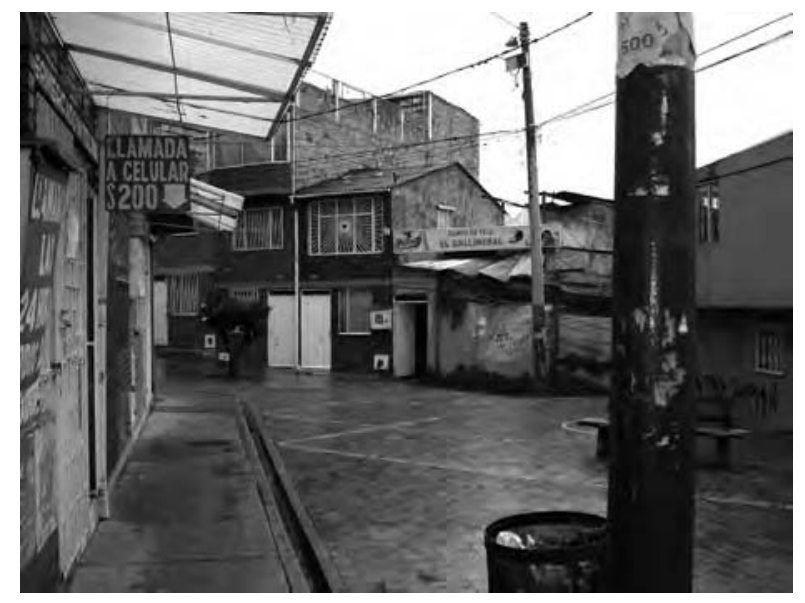

Foto del autor, 2009.

callejeras son el ejemplo más visible. Como lo muestran los estudios de caso, cada tipo de actividad brinda y permite formas particulares de uso y apropiación de los espacios públicos.

La actividad económica en los barrios se ve como una manera de generar ingresos adicionales para la familia; en ocasiones es incluso la principal fuente de ingresos. La vivienda "es también un lugar de producción" ${ }^{64}$; alquilar una habitación o "poner un negocio' en el frente de la casa son opciones que la gente generalmente considera. Este uso económico

64 Kellett y Tipple, 2000, p. 203.
FIGURA 14. VENTAS AMBULANTES EN EL BARRIO LA ANDREA.

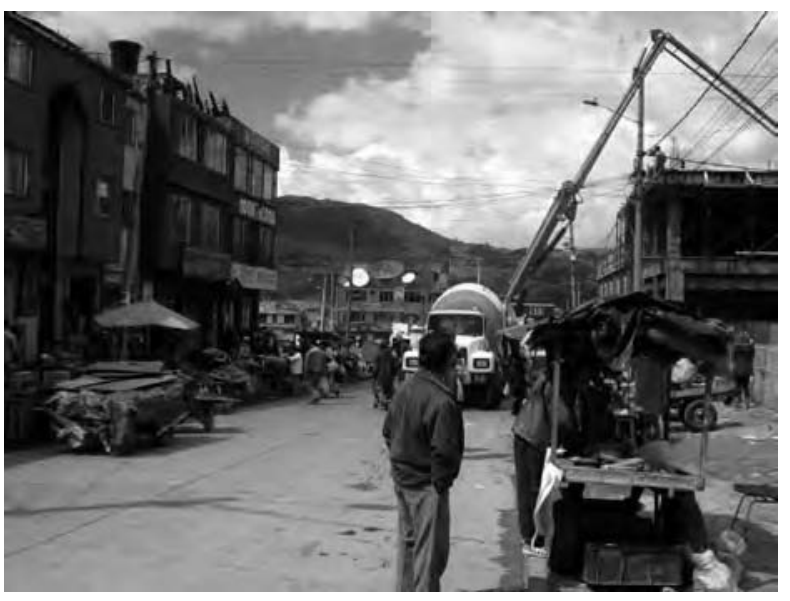

Foto del autor, 2009

de la casa refuerza la relación del residente con el espacio público, no sólo por la razón práctica del espacio interior reducido y la necesidad de participar en un intercambio social, sino también por motivos económicos. Las actividades comerciales realizadas desde la casa y en los espacios públicos van desde la venta de helados por la ventana de la sala, pasando por remodelaciones de construcción, hasta talleres de carpintería o fundición y supermercados medianos, que generan el uso y apropiación de las calles y parques que están frente 
a ella. En este rango de actividades se incluye la tienda, también conocida como miscelánea o panadería, que es tal vez la forma más común de comercio (figura 12).

Las tiendas no son sólo un lugar de intercambio comercial, sino también un centro social para la comunidad $^{65}$. El tendero es consejero y casi siempre es una persona que conoce bien el barrio y su gente. Los residentes van a la tienda no sólo a comprar víveres (generalmente 'fiados' ${ }^{36}$ ), incluso cerveza para tomarla en la tienda o afuera en el pavimento o en el parque, sino también para contar sus historias y enterarse de la vida de los demás ${ }^{67}$. Ciertamente las tiendas forman parte de la dinámica social y cultural de los barrios, y su relación con los espacios públicos es evidente. En este sentido se pueden ver como un espacio terciario o semipúblico, siguiendo la teoría de Carmona. En los seis estudios de caso se puede observar el uso y significado social de las tiendas, particularmente en asentamientos más antiguos y consolidados como La Andrea o el Danubio, donde existen diferentes tipos de tiendas. Entre ellos hay uno cuya aparición es relativamente reciente en los barrios y ha

65 Coen, y otros, 2008.

66 'Fiar' (dar crédito) no es sólo una transacción financiera sino también una tradición en los barrios populares. Con frecuencia, la gente prefiere comprar en la tienda en vez de ir al supermercado y está dispuesta a pagar un poco más si puede cancelar después. Esto también ayuda a hacer más cercana la relación entre el tendero y la gente.

67 Rojas y Guerrero, 1997. ganado un lugar importante en ellos, en términos tanto de relevancia práctica como social: la 'tienda de minutos' (figura 13). Es un local desde el cual se pueden hacer llamadas a teléfonos fijos o celulares y donde las personas pueden conectarse a Internet. Son cada vez más populares en los barrios y, al igual como sucede en otros países latinoamericanos $^{68}$, se están convirtiendo en el nuevo punto de encuentro, especialmente para la gente joven.

En cuanto a las actividades económicas desarrolladas directamente en los espacios públicos, la venta callejera es la más común. Los vendedores ambulantes son un fenómeno ampliamente extendido en Bogotá, cuya percepción está polarizada; por un lado, se ve como una manera válida de ganarse la vida para la gente pobre; y por otro, se puede ver como una invasión del espacio público que debe ser controlada ${ }^{69}$. Sin embargo, la segunda percepción no se escucha en los barrios populares, al menos no entre la comunidad. También es cierto que hay menos intercambio comercial en las calles del barrio que en el centro de la ciudad. Puede ser menos frecuente pero existe, y cuanto más consolidado sea el asentamiento, como sucede en La 
Andrea, más comercio callejero se observa (figura 14). No obstante, la mayoría de los estudios de caso muestran que la venta callejera es un factor que genera actividad en los espacios públicos y que también está directamente relacionada con lugares y hechos específicos, como el paradero de bus o el partido de fútbol de los domingos en el parque.

\section{Construcción social simbólica: Expresiones experienciales, emocionales, cognitivas y de relaciones de poder}

\section{EXPERIENCIALES Y EMOCIONALES}

Los espacios públicos se pueden ver como lugares producidos y construidos socialmente, "cuyo valor y significado no son inherentes a ellos' [...] sino que se construyen, se reproducen y se defienden ${ }^{70}$. La gente se relaciona con los lugares y los lugares se relacionan con la gente creando un vínculo emocional $^{71}$ o un apego subjetivo y afectivo ${ }^{72}$. En los asentamientos populares esta relación puede ser aun más fuerte puesto que las personas han estado involucradas con los lugares desde su creación.

\footnotetext{
70 Lombard, 2009, p. 64.

71 Groat, 1995.

72 Cresswell, 2004.
}

Esta relación gente-lugar se puede considerar como la construcción experiencial del espacio; y como ya se mencionó, se origina en el uso cotidiano de los lugares, que incluye los usos sociales, culturales y funcionales. El apego y la apropiación pueden ser las aproximaciones principales pero la asociación también tiene otras explicaciones como la territorialización, la personalización, el sentido de pertenencia y la identidad de los lugares que contribuyen a la identidad de individuos y comunidades.

\section{Manifestaciones sociales y culturales}

Las prácticas cotidianas y funcionales asociadas con los espacios públicos representan las distintas maneras como los habitantes se relacionan con esos lugares, construyendo apego a ellos y desarrollando estrategias de apropiación que en varios casos incluyen la transformación del espacio. Las actividades que involucran comer y beber en calles y parques son un buen ejemplo; en ellas, el lugar sufre modificaciones para acomodar sillas y hasta instalaciones para cocinar; el entorno completo pasa de ser un área tranquila de circulación a un lugar festivo y ruidoso. Esos lugares siguen estando en la memoria de la gente, generando apego. Siempre que sea posible, como sucede en La Andrea, el lugar donde se hacen estas manifestaciones se convierte en el "sitio oficial" (por ejemplo, la 
gradería donde se hace la "olla comunitaria") y se transforma formalmente.

\section{Procesiones religiosas}

Otra práctica cultural que contribuye a los procesos de apego y apropiación son las procesiones religiosas y otras actividades relacionadas que afectan los espacios públicos, por ejemplo ermitas en los parques e imágenes religiosas en la fachada de las casas. Éstas se pueden ver no sólo como expresiones puras de fe sino también como manifestaciones sociales y estéticas. Las procesiones, que se observan especialmente en Pascua pero también en otras fiestas religiosas como el Día de la Virgen, son manifestaciones sociales que incluyen varias actividades descritas a lo largo de este estudio. Las ermitas y las imágenes en las fachadas van más allá de una simple expresión de fe religiosa, para convertirse en manifestaciones estéticas. Como Hernández Bonilla ${ }^{73}$ encontró en las colonias populares de México, estas expresiones también se encuentran en los barrios de Bogotá -como en El Danubio y Los Cerezos, por ejemplo-, lo cual permite establecer relaciones adicionales de apego con quienes participan en su transformación visual y funcional. Dicho de otro modo, se puede afirmar que las manifestaciones religiosas estrechamente

73 Hernández Bonilla, 2004. ligadas a los espacios públicos pueden contribuir a la identificación emocional con el lugar o "identidad del lugar", definida ésta como "un valor cultural compartido por la comunidad, una comprensión colectiva de la identidad social entretejida con el significado del lugar"74.

\section{Manifestaciones físicas}

Las expresiones físicas o formales observadas en las fachadas que le dan forma a los espacios públicos también se pueden interpretar como prácticas de apego y apropiación. Es interesante señalar aquí que también se pueden entender como evidencia de la construcción experiencial del espacio. Por ejemplo, los colores brillantes de las fachadas pueden representar el deseo de sobresalir $^{75}$, o el enrejado se puede ver como una expresión de aspiración o ambición ${ }^{76}$. Ambos casos son manifestaciones del apego de las personas al lugar y su deseo de mostrar su presencia y su estatus económico o social. Claramente el espacio es transformado por estas incursiones, como lo es la percepción del mismo.

\section{LUGARES Y SUS NOMBRES}

Darle nombre a los espacios públicos se puede considerar una forma de establecer relaciones

Harner, 2001, p. 660

75 Carvajalino, 2004.

76 Kellett, 2008. 
compartidas con los lugares, lo que contribuye a identificarlos e identificarse con ellos ${ }^{77}$. En los 57 casos hay varios ejemplos: Parque Sueños de Vida, Parque Jardín de los Abuelos, Alameda El Progreso, Calle de la Unión y Parque Tanque Lagu$n a$, entre otros. Los nombres representan diferentes cosas: algunos representan aspiraciones (Sueños de Vida o El Progreso), otros recuerdan historias (La Unión o Tanque Laguna ${ }^{78}$ ) y otros expresan aquello que los residentes quisieran que el parque fuera (Jardín de los Abuelos). Pero todos conectan a la gente con el lugar y ayudan a construir apego y apropiación.

En los estudios de caso encontramos ejemplos de los nombres asignados a los lugares. El barrio Manuela Beltrán, donde está ubicado el parque Los Cerezos, lleva el nombre de un famoso personaje histórico de Colombia, quizás la única mujer reconocida en la historia de la independencia del régimen colonial. El parque de Villa Sonia se llama Parque por un Bien Común, el cual, junto con los ejemplos anteriores, expresa una aspiración de la comunidad. Hay diferentes nombres por diversas razones, pero

77 Bernardo y Palma-Oliveira, 2008.

78 La calle 'La Unión' recuerda la lucha vivida para construir la escalera que este proyecto logró. 'Tanque Laguna' hace recordar que el parque fue inicialmente una laguna en la cima de la colina donde la empresa de acueducto municipal tenía un tanque, y la lucha que se dio durante muchos años para lograr lo que se observa hoy. todos representan conexiones y ayudan a construir identidad.

\section{REPRESENTACIONES COGNITIVAS Y SÍMBOLOS}

El espacio no sólo se consume de manera social, cultural, funcional y experiencial; también se puede ver como un 'constructo mental', es decir, que no se aprende directamente sino que se llega a entender solamente a través de un complejo proceso de interpretación ${ }^{79}$. El espacio, por lo tanto, excede aquello que se percibe por los sentidos y puede ser entendido por lo que se percibe o construye en la mente. En otras palabras, el espacio puede ser no sólo 'lo que es' sino 'lo que pensamos que es', en una especie de "mapa mental o cognitivo de la realidad urbana con unas coordenadas interpretativas a través de las cuales pensamos, experimentamos, evaluamos y decidimos actuar en los lugares, espacios y comunidades donde vivimos" $"$.

De esta manera, el espacio también puede ser entendido como un conjunto de señales o símbolos que encierran significado y valores, los cuales están centrados "en el papel que desempeñan los

79 Moore, 1983.

80 Soja, 2000 , p. 234. 
objetos, los acontecimientos y las apariencias"81. Lo que se percibe o se construye en la mente en términos de representación cognitiva del espacio como imaginario urbano ${ }^{82}$ y las representaciones simbólicas del espacio como objetos, acontecimientos y apariencias con significado y valores, abren una posibilidad complementaria de entender los espacios públicos en los asentamientos populares. Esta 'construcción mental' del espacio se nutre directamente del uso que se le dé, de la experiencia que se viva en él y de la relación que se tenga con el entorno físico, la lengua, las expresiones formales y el significado.

"Los seres humanos necesitan conexiones con el mundo; algunas de ellas se las proporcionan los espacios que habitan y las actividades que allí ocurren" ${ }^{83}$. En los asentamientos populares, las representaciones cognitivas del espacio y los imaginarios urbanos se pueden considerar herramientas de conexión con un presente urbano y moderno, representado por la ciudad y sus patrones culturales de consumo, con un futuro imaginado ${ }^{84}$, o con un pasado tradicional o rural ${ }^{85}$-y muy probablemente, con todos ellos-. La mayoría de las manifestaciones sociales y culturales relacionadas con los espacios públicos, como se explicó antes,

81 Madanipour, 1996, p. 69.

82 Silva, 1992 y Soja, 2000.

83 Carr y otros, 1992, p. 187.

84 Kellett, 2009.

85 García Canclini, 1989. se pueden interpretar como tentativas de conexión con el pasado, el presente y el futuro.

En los barrios es común "observar" señales y símbolos tangibles e intangibles cuyo origen tiene que ver con la historia de la comunidad, como García, Giuliani y otros ${ }^{86}$ señalan. En el barrio Nueva Argentina, el parque mismo es un símbolo de la lucha de la comunidad por ganar ese espacio y hacer que funcione. Por motivos similares, en Tanque Laguna la comunidad decidió construir en medio del parque una cruz con dos placas conmemorativas de la lucha que dio paso a su creación y el logro que su construcción representa. Sin embargo, podría decirse que la mayoría de los símbolos que se encuentran en los barrios provienen del uso cotidiano de los espacios públicos. Quizás uno de los más importantes es la tienda. Los seis estudios de caso muestran que éste no sólo es un lugar de intercambio comercial sino también un centro social para la comunidad, un punto de referencia para la gente del barrio y el primer lugar de encuentro de visitantes y recién llegados. El paradero de bus es otro punto de referencia importante; en lugares como Aguas Claras su importancia es aun mayor ya que a su alrededor se desarrollan diversas actividades sociales. Las imágenes religiosas en las 
fachadas de las casas y las ermitas también juegan un papel relevante en la construcción simbólica del espacio público, pues transmiten un significado a la mayoría de los miembros de la comunidad y contribuyen a que el lugar sea lo que es, como ocurre en El Danubio y Los Cerezos. Por último, hay otros sitios en el barrio a los que las comunidades les han asignado un significado por diversas razones; por ejemplo, la casa azul brillante de José Emilio en Los Cerezos es un punto de referencia, pero cualquier esquina puede adquirir un significado particular. Las esquinas del barrio pueden crear patrones de identidad según la gente que las utilice: la esquina del músico, la esquina de los adolescentes, la esquina del chisme, etcétera ${ }^{87}$.

\section{RELACIONES DE PODER: EL CONFLICTO}

Dentro de la construcción social y simbólica del lugar se encuentran las relaciones de poder que se tejen entre los pobladores, y entre éstos y los estamentos civiles y gubernamentales. Estas relaciones tienen su manifestación en el conflicto y se materializan especialmente en los espacios públicos, los cuales tienen un significado político y un simbolismo de poder ${ }^{88}$. En este aspecto, es común el conflicto entre los diferentes actores involucrados en su creación, transformación y uso. Van Deussen ${ }^{89}$

87 Ontiveros y De Freitas, 2006, p. 231.

88 Madanipour, 1999 y Rosenthal, 2000.

89

Van Deussen, 2002, p. 150. afirma que "el espacio público siempre es un espacio de conflicto; es un sitio de lucha para ver quién lo controla y quién tiene acceso, quién determina su constitución y como se reproduce". En términos del uso, las restricciones de acceso y control de los espacios abiertos y las actividades relacionadas son las principales cuestiones que provocan conflicto entre los habitantes de los barrios populares.

Los casos muestran dos temas principales de conflicto: uno, por la defensa de los derechos sobre un territorio, el cual puede estar relacionado con el acceso, control y seguridad: "Por cerca de dos meses tuvimos el mismo problema, pues hinchas del Santa Fé [equipo local de fútbol] venían a celebrar en nuestro parque, se emborrachaban, fumaban droga yhacian ruido, generando incomodidad pero también inseguridad. Llamábamos a la policía y se iban, pero volvian el fin de semana siguiente. Logramos finalmente hablar con ellos y parece que entendieron porque no han vuelto" (entrevista con Rosa, del barrio el Danubio, noviembre 2008). El otro tema se relaciona con los conflictos surgidos por el uso cotidiano: "No es raro ver los domingos que han dejado carros parqueados en el parque, de gente que seguramente pasó la noche bebiendo en alguna vivienda cercana" (entrevista con María, del barrio Manuela Beltrán, diciembre 2008). Los dos temas se pueden superponer, ya 
que un conflicto que comienza como un problema del uso cotidiano se convierte en un asunto territorial y viceversa. El uso y apropiación de los espacios abiertos por parte de los jóvenes es un buen ejemplo de esto, y también confirma que los conflictos son por las relaciones de poder.

\section{Conclusiones}

En este artículo se ha hecho un análisis de la construcción social de los espacios públicos en los asentamientos populares. Los pobladores transforman los espacios públicos al usarlos e interactuar con ellos pero esta interacción también los transforma, como sostienen Holloway y Hubbard hablando de la relación entre la gente y el lugar ${ }^{90}$. Los pobladores transforman sus espacios urbanos con el uso cotidiano, funcional y simbólico; aparecen materas con flores, bancos para sentarse, canchas para jugar, caminos para acortar el paso a través de un parque y una venta de helados en alguna esquina, entre otras varias iniciativas que los usuarios de estos lugares desarrollan. También aparecen las transformaciones simbólicas mediadas por la experiencia y la cognición, pues una esquina cualquiera puede tener gran significado para una comunidad porque allí sucedió algo de importancia, una calle puede ser un lugar que evoque recuerdos, los colores de las viviendas que dan

90 Holloway y Hubbard, 2001. a un parque pueden querer comunicar un mensaje. El poblador transforma sus espacios, pero también sus dinámicas sociales se ven transformadas por el espacio. Los horarios de uso de ciertos lugares, la manera de reunirse en grupos grandes o pequeños y la función predominantemente recreativo-deportiva (en contra de la contemplativa y de activismo político-comunitario) de los espacios públicos en los barrios, entre otros ejemplos, hablan de estas transformaciones sociales.

Esta investigación ha verificado la estrecha relación entre la gente y el lugar en los espacios públicos de los barrios populares, confirmando que estos espacios son públicos en términos de accesibilidad y propiedad, pero no son tan públicos en términos de uso y apropiación. En partes más afluentes de la ciudad, las personas normalmente se relacionan con su entorno sólo a través del uso que le dan porque son otros quienes han construido el espacio para ellas. La forma y el lenguaje de diseño han sido escogidos por urbanistas y arquitectos, en el mejor de los casos interpretando las necesidades y expectativas de la gente pero también siguiendo las dinámicas y tendencias de su profesión. Se podría decir que la relación gente-lugar tiende a ser débil. En los asentamientos populares la lógica es distinta, pues la gente no sólo se relaciona con el entorno construido usándolo, sino también produciéndolo y dándole forma. La materialidad y 
el lenguaje de diseño observados corresponden en gran parte a lo que la gente ha decidido, siguiendo las dinámicas y posibilidades de los individuos y las comunidades. Hay una relación "a largo plazo" entre la gente y el lugar; los habitantes populares se involucran profundamente en la creación de sus propios lugares, que en muchos casos incluye lucha y sacrificio, y la relación se hace más profunda con el uso cotidiano.

Los espacios públicos son un producto social "creado a partir de las exigencias del uso cotidiano y las luchas sociales de los habitantes urbanos" Estos espacios son producidos y transformados socialmente por "las acciones tanto individuales como colectivas de los sujetos que nacen y mueren, que sufren y que actúan"92. La transformación de esos espacios continúa con su construcción social "a través de los intercambios sociales de la gente, sus recuerdos, sus imágenes y su uso cotidiano del entorno físico" 93 . Se podría decir que el producto es el resultado de unas prácticas de producción y construcción social, como lo señala Harvey ${ }^{94}$. En el mismo contexto, Rapoport ${ }^{95}$ afirma: "[los habitantes populares] generalmente tratan de crear entornos y elementos que sirvan de apoyo a ciertos componentes de su cultura". De igual manera

91 Crawford, 1995, p. 7

92 Lefebvre, 1991, p. 3

93 Low, 1996, p. 861-862.

94 Harvey, 1996

95

Rapoport, 1988, p. 58.
Carr, Francis y otros ${ }^{96}$ explican que los espacios públicos son un espejo de los valores sociales, un espejo que refleja realidades físicas, sociales, políticas y económicas. Los espacios públicos son partes constituyentes de los asentamientos populares que se producen y construyen socialmente mediante las interacciones cotidianas. Se podría decir que la materialidad observada es el resultado de estas interacciones y que en el camino también se construyen y transforman significados. Es posible entonces confirmar lo que Madanipour ${ }^{97}$ señaló al referirse a la necesidad de ver los espacios urbanos como identidades espaciales, sociales y simbólicas dentro de las ciudades: "Sólo desde una concepción fragmentada y estática del espacio podemos ver los procesos sociales separados del espacio físico y mental [...]. Ellos son, por definición, los componentes de un concepto más comprehensivo del espacio".

La pregunta que surge entonces es iqué podemos aprender de la construcción social del espacio público en los barrios populares para el desarrollo de política urbana, de decisiones de planificación, y de diseño de espacios públicos? En teoría mucho, en la práctica muy poco, quizás nada. Mucho, ya que conocer en detalle cómo se usan funcional,

96 Carry otros, 1992.

97 Madanipour, 1996, p. 30 
cotidiana y simbólicamente los espacios urbanos en estos barrios ofrecería variables reales y concretas sobre lo que estas comunidades quieren, necesitan y aspiran, en lugar de ser objeto de las necesidades y gustos de los diseñadores de turno y de cómo ellos piensan que deben vivir las personas. Poco o quizás nada, ya que la construcción social de espacio sigue una lógica distinta a la de la planeación, la lógica del mejoramiento continuo, de la transformación gradual, del desarrollo progresivo. Retomando a Romero, Mesías y otros ${ }^{98}$, la producción social de hábitat es una realidad en América Latina, y puede entenderse como una alternativa legítima. Sin embargo, considero que hay acercamientos posibles entre estas dos lógicas, y puede haber ganancias significativas en torno al mejoramiento del espacio habitable y de la calidad de vida de las comunidades, si se aúnan visiones, esfuerzos y recursos, y si al centro de ese trabajo se coloca a la gente con sus reales necesidades y aspiraciones.

\section{Bibliografía}

ALSAYYAD, Nezar. Informal housing in a comparative perspective. On squatting, culture, and development in a Latin American and a Middle Eastern context. [En línea]. Review of Urban and Regional Development Studies. 5(1): 3-18. 1993.

98 Romero y otros, 2004.

174 revista invi № 78 / Agosto 2013 / Volumen № 28: 143-178
ISSN: 1467-940X. Disponible en: http://dx.doi. org/10.1111/j.1467-940X.1993.tb00120.x.

AVERWEG, Udo Richard, y VILLANUEVA, Eduardo. Peruvian cabinas públicas, Does Policy provide practice or does practice provide Policy? [En línea]. Information Technology in Developing Countries. 19(2): 9. 2009. Disponible en: http://www. iimahd.ernet.in/egov/ifip/jun2009/udo-averweg. htm.

BEARDSLEY, John y WERTHMANN, Christian. Improving Informal settlements: ideas from Latin America. [En línea]. Harvard Design Magazine. (28): 31-35, 2008. Disponible en: http://www. gsd.harvard.edu/images/content/5/5/553201/28BeardsleyWerthmann.pdf.

BERNARDO, F. y PALMA-OLIVEIRA, José. Exploring place and identity: the importance of place to the self-definition. En: BONAIUTO, Marino; BONNES, Mirilia; NENCI, Annamaria y CARRUS, Giuseppe. 20th IAPS International Conference: Urban Diversities, Biosphere and Well-being. Designing and Managing Our Common Environment. Rome, International Association for People Environment Studies. 2008.

BRILLEMBOURG, Alfredo y KLUMPNER, Hubert. Roles of engagement: Caracas and the informal city. En: HERNÁNDEZ, Felipe; KELLETT, Peter y ALLEN, Lea. Rethinking the informal city: critical perspectives from Latin America. Oxford, Berghahn Books. 2010. p. 119-36. 
CARMONA, Matthew. Contemporary public space: critique and classification, part one: critique. [En línea]. Journal of Urban Design. 15(1): 123-48, 2010. Disponible en: http://dx.doi. org/10.1080/13574800903435651.

CARMONA, Matthew; HEATH, Tim; OC, Tanner y TIESDELL, Steven. Public places, urban spaces. Oxford: Architectural Press. 2003.

CARR, Stephen; FRANCIS, Mark; RIVLIN, Leanne y STONE, Andrew. Public space, environment and behaviour series. Cambridge, Cambridge University Press. 1992.

CARVAJALINO BAYONA, Hernando. Estética de lo popular: los engalles de la casa. En: Expresión formal de la vivienda espontánea. Bogotá, Barrio Taller. 2004. Serie Ciudad y Hábitat Nº11.

COEN, Stephanie E.; ROSS, Nancy A. y TURNER, Sarah. "Without tiendas it's a dead neighbourhood": The socio-economic importance of small trade stores in Cochabamba, Bolivia. [En línea]. Cities. 25(6): 327-39, 2008. ISSN 02642751. Disponible en: http://dx.doi.org/10.1016/j. cities.2008.06.003.

CRAWFORD, Margaret. Contesting the public realm: struggles over public space in Los Angeles. Journal of Architectural Education. 49(1): 4-9, 1995. ISSN 1046-4883.

CRESSWELL, Tim. Place, a Short Introduction. Oxford: Blackwell. 2004.

DONOVAN, Michael. Informal cities and the contestation of public space: the case of Bogotá's street vendors
1988 - 2003. [En línea]. Urban Studies. 45(1): 2951. 2008. ISSN 1360-063X. Disponible en: http:// dx.doi.org/10.1177/0042098007085100.FIORI, Jorge y BRANDAO, Zeca. Spatial strategies and urban policy: urbanism and poverty reduction in the favelas of Rio de Janeiro. En: HERNÁNDEZ, Felipe, KELLETT, Peter y ALLEN, Lea. Rethinking the Informal City: Critical Perspectives from Latin America. Oxford, Berghahn Books. 2010. p. 181-206

GARCÍA CANCLINI, Néstor. Culturas híbridas. México, DF, Editorial Grijalbo. 1989.

GARCÍA, Isabel; GIULIANI, Fernando y WIESENFELD, Esther. Community and sense of community: the case of an urban barrio in Caracas. [En línea]. Journal of Community Psychology. 27(6): $727-740$, 1999. ISSN 1520-6629. Disponible en: http://dx.doi.org/10.1002/(SICI)15206629(199911)27:6<727::AID-JCOP7>3.0.CO;2-Y/ abstract.

GEHL, Jan. Life between buildings, using public space. New York, Van Nostrand Reinhold. 1987.

---- Making room for people. En: NYSTROM, L. City and culture: cultural processes and urban sustainability. Stockholm, Swedish Urban Environment Council. 1999. p. 235-47.

GROAT, Linda. Place, aesthetic evaluation and home. En: GROAT, Linda. Giving places meaning: readings in environmental psychology. London: Academic Press. 1995. p. 1-26.

HARNER, John. Place identity and copper mining in Sonora, México. [En línea]. Annals of the 
Association of American Geographers. 91(4): 660 80. 2001. ISSN 1467-8306. Disponible en: http:// dx.doi.org/10.1111/0004-5608.00264.

HARVEY, David. Social process and spatial form. En: JEWSON, N. y MACGREGOR, S. Transforming cities: contested governance and new spatial divisions. London, Routledge. 1996.

HERNÁNDEZ BONILLA, Mauricio. Transforming public spaces in México: the case of colonias populares in Xalapa. Newcastle Upon Tyne, University of Newcastle Upon Tyne. 2004.

HERNÁNDEZ GARCÍA, Jaime. El parque de mi barrio: production and consumption of open spaces in popular settlements in Bogotá. Newcastle Upon Tyne, University of Newcastle Upon Tyne. 2010.

HOLLOWAY, Lewis y HUBBARD, Phil. People and place: the extraordinary geographies of everyday life. Harlow, Pearson Education. 2001.

JIMÉNEZ DOMÍNGUEZ, Bernardo. Urban appropriation and loose spaces in the Guadalajara cityscape. En: FRANCK, Karen y STEVENS, Quentin. Loose space. Possibility and diversity in urban life. London, Routledge. 2007. p. 96-112.

KELLETT, Peter. Constructive Journeys: dwelling consolidation and social practices in a squatter settlement. Durham, University of Durham, 2008.

---- Constructing home: the production and consumption of popular housing in Northern Colombia. Newcastle Upon Tyne, University of Newcastle Upon Tyne. 1995.

176 revista invi № 78 / Agosto 2013 / Volumen № 28: 143-178
---- Original copies? Imitative housing forms and dwelling practices in a squatter settlement. En: Anthropological and archaeological imaginations: past, present and future. Bristol: Association of Social Anthropologists (ASA). 2009.

KELLETT, Peter y TIPPLE, Graham. The home as workplace: a study of income-generating activities within the domestic setting. [En línea]. Environment and Urbanization. 12(1): 203-214, 2000. ISSN 0956-2478. Disponible en: http://dx.doi. org/10.1177/095624780001200115.

LEFEBVRE, Henry. The production of space. Oxford, Blackwell. 1991.

LOMBARD, Melanie. Making place in the city: placemaking in urban informal settlements in México. Sheffield, University of Sheffield. 2009.

LOW, Setha. On the plaza, the politics of public space and culture. Austin, University of Texas Press. 2000.

---- Spatializing culture: the social production and social construction of public space in Costa Rica. [En línea]. American Ethnologist. 23(4): 861-879. 1996. ISSN 1548-1425. Disponible en: http:// dx.doi.org/10.1525/ae.1996.23.4.02a00100

MADANIPOUR, Ali. Design of urban space. An inquiry into a socio-spatial process. Chichester, Wiley. 1996.

---- Public and private spaces of the city. London, Routledge. 2003.

-.-- Why are the design and development of public spaces significant for cities? [En línea]. Environment

ARTíCULO: Construcción Social de Espacio Público en Barrios Populares de Bogotá / Jaime Hernández García 
and Planning B: Planning and Design. 26(6): 879891. 1999. ISSN 1472-3417. Disponible en: http:// dx.doi.org/10.1068/b260879.

MERRIFIELD, Andrew. Place and space: a lefebvrian reconciliation. Transactions of the Institute of British Geographers, New Series. 18(4): 516-531. 1993. ISSN: 1475-5661.

MILES, Malcolm. The uses of decoration. Essays in the architecture everyday. Chichester, Wiley. 2000.

MILES, Mathew B. y HUBERMAN, Michael. Qualitative data analysis. London, Sage Publications. 1994.

MOORE, G. Knowing about environmental knowing: the current state of theory and research on environmental cognition. En: PIPKIN, J.; LA GORY, M. y BLAU, J. Remaking the city: social science perspectives on urban design. Albany, NY, University of New York Press. 1983. p. 21-50.

NIÑO MURCIA, Carlos y CHAPARRO VALDERRAMA, Jairo. El espacio público en algunos barrios populares de la Bogotá actual. En: La calle: lo ajeno, lo público y lo imaginado. Bogotá, Barrio Taller. 1997. p. 71-88. Serie Ciudad y Hábitat Nº4.

OLIVER, Paul. Built to meet needs: cultural issues in vernacular architecure. Oxford, Elselvier. 2006.

ONTIVEROS, Teresa y DE FREITAS, Julio. Hacia la comprensión del uso de los espacios públicosprivados en los territorios populares contemporáneos. Cuaderno Urbano: espacio, cultura y sociedad. (5): 217-234, 2006. ISSN 1666-6186.

ARTíCULO: Construcción social de espacio público en barrios populares de Bogotá / Jaime Hernández García
PARAMO, Pablo y CUERVO PRADOS, Mónica. Historia social situada en el espacio público de Bogotá desde su fundacion hasta el siglo XIX. Bogotá, Universidad Pedagógica Nacional. 2006.

PROSHANSKY, H; FABIAN, A. y KAMINOFF, R. Place identity, physical world socialization of self. [En línea]. Journal of Environmental Psychology. 3(1): 5783. 1983. ISSN 0272-4944. Disponible en: http:// dx.doi.org/10.1016/S0272-4944(83)80021-8.

RAPOPORT, Amos. Sociocultural aspects of man-environment studies. En: RAPOPORT, Amos. The mutual interaction of people and their built environment: a cross-cultural perspective. The Hague, Mouton. 1976. p. 7-35.

---- Spontaneous settlements as vernacular design. En: PATTON, Carl. Spontaneous Shelter: international perspectives and prospects. Philadelphia, Temple University Press. 1988. p. 51-77.

RELPH, Edward. Place and placeness. London, Pion Limited. 1976.

RIAÑO, Yvonne. Understanding the cultural dynamics of popular habitats: from spatial activity patterns to local identity in the barrios of Bogotá, Colombia. En: BASSAND, M., ed. y BOLAY, J., ed. International Colloquium: Creative habitat, culture and participation. Laussane, Institut de Recherche sur l'Envrionment Construit, Comission Nationale Suisse pour l'UNESCO. 1990.

ROJAS S., Edilsa y GUERRERO G., Martha. La calle del barrio popular: fragmento de una ciudad fragmentada. En: La calle: lo ajeno, lo público y lo

revista invi № 78 / Agosto 2013 / Volumen №28: 143-178 177 
imaginado. Bogotá, Barrio Taller. 1997. p. 21-49. Serie Ciudad y Hábitat Nº4.

ROMERO, Gustavo; MESÍAS, Rosendo; ENET, Mariana; OLIVERAS, Rosa; GARCÍA, Lourdes; COIPEL, Manuel y OSORIO, Daniela. La participación en el diseño urbano y arquitectónico en la producción social del hábitat. México DF, CYTED. 2004.

ROSENTHAL, Anton Benjamin. Spectacle, fear, and protest: a guide to the history of urban public space in Latin America. [En línea]. Social Science History. 24(1): 33-73, 2000. ISSN 1527-8034. Disponible en: http://dx.doi.org/10.1215/01455532-24-1-33.

RUEDA GARCÍA, Nicolás. La ciudad que no conocemos. En: SOCIEDAD Colombiana de Arquitectos. Cien años de arquitectura en Colombia. XVII Bienal De Arquitectura. Bogotá, Sociedad Colombiana de Arquitectos. 2000.
SEGOVIA, Olga y OVIED0, Enrique. Espacios públicos en la ciudad y el barrio. En: Espacio público, participación y ciudadanía. Santiago, Sur. 2000. p. 51-69. ISBN 956-208-061-7.

SILVA, Armando. Imaginarios urbanos, Bogotá y Sao Paulo: cultura y comunicación en América Latina. Bogotá, Tercer Mundo Editores. 1992.

SOJA, Edward. Postmetropolis. Critical studies of cities and regions. London, Blackwell. 2000.

UNCHS. The challenge of slums. Global report on human settlements 2003. London, Earthscan. 2003.

VAN DEUSSEN, R. Public space design as class warfare: urban design, the 'right to the city' and the production of Clinton Square, Syracuse, NY. [En línea]. GeoJournal. 58(2-3): 149-158, 2002. ISSN 1572-9893. Disponible en: http://dx.doi. org/10.1023/B\%3AGEJO.0000010834.17907.5e\#. 